Thorax (1948), 3, 189.

\title{
A PROVOCATIVE TALK ON PULMONARY TUBERCULOSIS*
}

\author{
BY \\ H. MORRISTON DAVIES
}

Some time ago I had decided never again to read or give a paper. Had my colleagues permitted, I should have adhered to this most sensible decision. They have, however, demanded a swan song from me. The blame is theirs.

\section{LOOKING BACK}

It is natural that to-day I should choose the subject of pulmonary tuberculosis, and human that I look back over the past thirty-eight years. It was in 1910 that I went to Berlin to the Surgical Congress there and heard Sauerbruch, Friedrich, Brauer, and Wilms give their epoch-making papers on thoracic surgery. There they gave demonstrations of their "überdruck" and "unterdruck" apparatus for the maintenance of expansion of the lungs in open chest operations, and discoursed on the "extrapleural paravertebral thoracoplasty" and on the Wilms' operationthe resection of the costal cartilages in front as well as the posterior segments of the ribs.

The next four years were certainly exciting ones for me : often too much so. Everything was new and, therefore, in a way unknown. I had not seen any of the operations done. The attitude of many of my colleagues was anything but friendly, and the sight of me and my stethoscope was anathema to the physicians.

My first interests were the invention of and the making of a new type of "überdruck" apparatus, known familiarly as my "fire engine." $\dagger$ This, once $I$ had persuaded the youngest of our anaesthetists to become acquainted with it, worked wonderfully well. It was soon outclassed by the very much simpler ideas of Meltzer and Auer and by the Shipway apparatus. These have in turn become progressively modified, until now the open chest has ceased to figure even as an anxiety.

Of greater importance was my installation of my own $x$-ray apparatus in a research room at

* Read before the Thoracic Society in Birmingham, July, 1948. †Brit. med. J., 1911, 2, 61.
University College Hospital. This was necessitated by the refusal of the radiologist to co-operate and the emphatic assertion of almost everyone that radiographs of the chest were useless in diagnosis. I begged, borrowed, and sometimes stole the chest cases, and, by what must have been a most annoying persistence, gradually got others interested in my discoveries.

Most of these discoveries are commonplace these days, but in 1911 and 1912 they were really exciting. One such was in a woman who for 20 years had alternately attended a chest hospital for her dyspnoea or a general hospital on account of gastric symptoms. As you will guess, she had a diaphragmatic hernia. I used her so energetically as propaganda for the value of radiographs that she got bored and vanished. Another had been tossed to me by a physician so that I could waste a plate on a case of chronic bronchitis. The man had no other signs, and it amused me to demonstrate a tumour in the lower lobe, unrecognizable by clinical examination. Shortly after he produced prune-juice sputum and I was sternly reproved for diagnosing carcinoma. I added to this disapproval in January, 1913, by doing a dissection lobectomy, $\ddagger$ using my " fire engine." I am interested, on re-reading my notes, to find that even then the importance of covering the stump of the sutured bronchus was recognized. He did well for six days, but died on the eighth from empyema plus bronchitis. At necropsy there was no bronchial fistula.

\section{CHONDRECTOMY}

The mention of bronchitis leads me to ask your indulgence for one further digression from the title of my paper : but it is to ask for information. I never hear anything nowadays of the operation of chondrectomy for the rigid dilated chest with associated emphysema, dyspnoea, and cyanosis. Yet in 1912 and 1913 I removed the second to

$\ddagger$ Brit. J. Surg., 1913, 1, 228. 
the fifth costal cartilages on the right side in three such cases. The first, who had been bedridden, was able within a fortnight to walk up a flight of stairs without any distress. Unfortunately he returned after a period of convalescence so pleased with himself and the feeling of freedom in the right chest that he overpersuaded me to operate on his left, which still felt tight. So he died. The other two did well. One, a fairly young man, was seen ten years later by E. K. Martin. He had been a market gardener and apparently, according to Martin, had no trouble other than chronic cough till two years before this later date, when he developed symptoms due to cardiac disease. One interesting point arises from the notes: even then the use of procaine hydrochloride into the intercostal nerves to allay post-operative pain which interfered with coughing was recognized.

\section{Artificial Pneumothorax}

To return to my proper subject. In those early years artificial pneumothorax was already established abroad and Vere Pearson and Clive Rivière had introduced and established it into this country. The trouble was that it was done without radiographic control, which sometimes led to some near-tragedies. I expect that the number of contra-selective collapses (a term not then invented) was even greater than to-day. Even though I had radiographic control I was unquestionably often guilty, from a spirit of optimism or cowardice, of continuing treatment rather than acknowledging failure. Even then there was controversy over the relative claims of "pleural shock" and "air embolism." Then, as now, there was the teridency to give refills of an approximate equal quantity of air instead of being guided by the pressures. I deplore this greatly. Time without number I find that if, say, $400 \mathrm{c.cm}$. of air has been the previous amount of a refill, 400 c.cm. continues to be the amount of each successive refill. This is, of course, wrong: the manometric intrapleural pressures should be the guide, provided, that is, that your patient lies in approximately the same position on each occasion. If the pressures are disregarded in favour of a fixed quantity of air, no allowance is made for the possible presence of a small effusion on one occasion, or the absorption of it on another: none for the possible gradual thickening of the pleura, or rate of absorption of the air; or displacement of the mediastinum, or for changes in the lung parenchyma. I do not say that the end-pressures should be the same from the first to the last. In my opinion the optimum pressure varies not only in different cases but from time to time in the same patient. That is one advantage of radiographic control.

Adhesion Section.-Adhesion section was not done in those early years. I tried once the open division of a large band through a thoracotomy. Unfortunately an effusion which developed leaked through the wound and caused a fistula and made me shy at further attempts. In those early days I made other attempts at the sectioning of lateral cords : attempts which shame me to think of. I had a very long streamline tenotome made which I pushed through the chest wall, under radiographic control, and sawed through the band. My luck was better than I deserved : one only of some halfdozen cases developed anything like a serious haemothorax. All the cases survived, but I fear none benefited. Then came the thoracoscope and cautery. I fumbled at first with Chandler's-a maddening instrument that invariably went wrong at the critical moment. The dual cannulascope and cautery seemed to solve the problem, but, unfortunately, the fear of bleeding vessels led to the use of diathermy before section, and I shudder to think of the number of pyo-pneumothorax tragedies which resulted before that method was abandoned in this country. I fear it is still in use elsewhere. Then came enucleation: also the realization that large vascular adhesions to tension surface cavities could not always be cut with impunity, and so we have reached the comparative safety of to-day. Here again each case must be judged individually and on experience (Plate II $a$ and $b$ ).

None the less there are still many debatable points in the matter of adhesion section. I would emphasize that every case of pneumothorax without complete, effective collapse should be thoracoscoped, even if no adhesion is visible on the $x$-ray film. Sometimes there are posterior adhesions, visible only when the patient is rotated almost on to his face. These may interfere with the success of the artificial pneumothorax equally with apical and lateral bands. The sooner, in my opinion, adhesions are divided, the better: any time from three weeks after induction. It is possible that some apical adhesions may not be sufficiently stretched by then, but if there are others which can be freed, this will aid the stretching of the remaining ones. I think also that it is of immense importance when faced with a short, thick, massive adhesion to try to decide whether or not it is completely divisible in one sitting. An incompletely divided adhesion of this character is very often followed by an effusion, and later 
completion of the separation is impossible. It is better to leave these untouched and, if necessary, abandon the artificial pneumothorax.

Obviously the success of any division is not just the technical change in the lung resulting from section but the ultimate clinical result of the artificial pneumothorax as shown by cavity closure and sputum conversion. Peter Edwards and his colleagues emphasize the importance of freeing the apex of the lung to the level of the clavicle, and say that adhesions to the medial thoracic wall below this level " are in most cases without effect on the course of the pneumothorax, and that operation in this area can be most meddlesome and dangerous."

With this, in the main, I agree, though I have seen adhesions over the root of the lung and azygos vein interfering with collapse by torsion of the lung. It is for this type of case, as well as others in which the closed pneumolysis would be dangerous, that division by direct vision through a thoracotomy is the method of choice. I do not think we are making full enough use of this method yet in this country. One reason for such hesitancy is, I believe, the fear of a resulting haemothorax. It is only right that such a possibility should be borne in mind and meticulous care in securing complete haemostasis ensured.

Results of Artificial Pneumothorax.-By and large the results of artificial pneumothorax are disappointing, but that is largely our fault. All these years we have been learning by the costly process of trial and error. Now we know that the results of a good collapse by artificial pneumothorax, combined often with an efficient division of adhesions, are mostly good. We know also that the results of contra-selective or ineffective collapse are bad, and, further, that artificial pneumothorax in some of these cases, or when there is tracheo-bronchial tuberculosis or persistent surface or tension cavities, is not only bad but often dangerous (see Figure). One great difficulty is that there are still too many sanatoria or centres for which the facilities for major surgery are not yet available; in consequence there is in these places a reluctance to abandon an active pro-

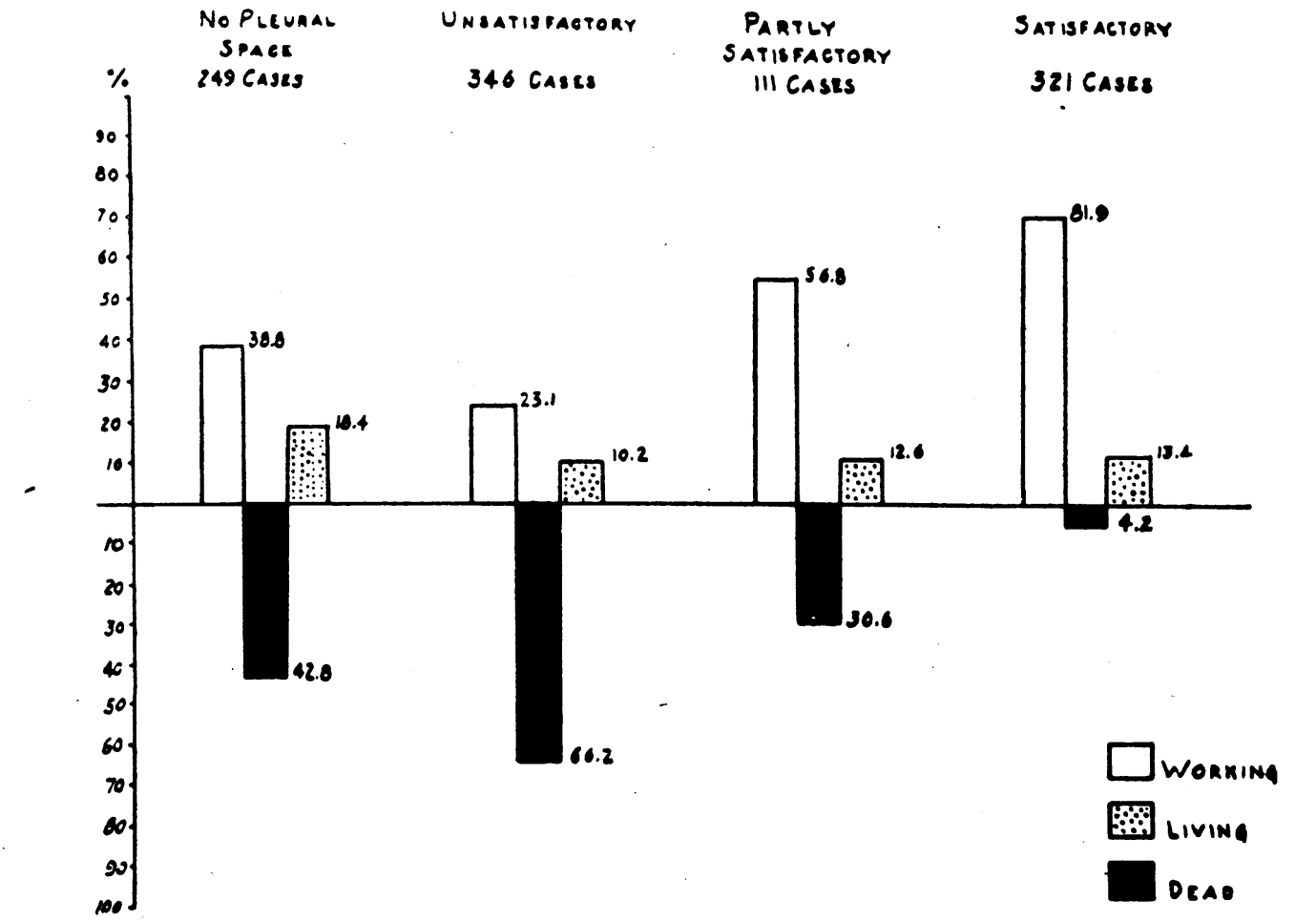

FIGURE.-Statistical graph emphasizing the role of free pleural space in determining the effect of pneumothorax on prognosis (after Jennings, Mattill, and Nemec). 
cedure, since no alternative is available. Let us hope that within another five years this unfortunate state of affairs will be remedied, and that the necessity of the immediate abandonment of an unsatisfactory artificial pneumothorax in favour of major surgery will be recognized-and the means for this made available.

Length of Maintenance.-For how long should an artificial pneumothorax be maintained ? I gather the average period-I am talking now only of cases in which the collapse has been completely effective and all adhesions divided -is three years. Why three years? Are the cavities necessarily closed in three years? Is there no fear of the tension strain of re-expansion reopening the cavities? In a lung where there have been extensive changes and resulting fibrosis, how much shifting of the mediastinum and consequently emphysema of the opposite lung (even after a phrenic paresis) will be produced ? We surgeons fear emphysema and the resultant dyspnoea after a pneumonectomy ; why not after a fibrosed lung is pulled out and the mediastinum dragged across ? I maintain that when a really efficient artificial pneumothorax control has been attained and the active processes of the disease have quiesced the fear of effusions is minimal. The patient, moreover, has a feeling of well-being and assurance. Why, then, let the lung reexpand? There are those who talk of the danger of bronchiectasis. Yes, if there has been an absorption collapse due to tracheobronchial tuberculosis; but then the artificial pneumothorax should have been abandoned long since. There is the fear of progressively thickening pleura: this can take place within a year or less: do you necessarily give up the artificial pneumothorax at the first sign of thickening ? In a properly selected case neither I nor the patient have ever regretted the maintenance of an artificial pneumothorax, even up to ten years. Doubtless there are few who will agree with me.

TUBERCulous EfFusions.-Tuberculous effusions complicating artificial pneumothorax can be divided broadly into three groups. There are the transient and usually small effusions and, at the other end of the scale, the intensely acute effusions. These latter have often to be aspirated sooner or later because of the persistent high pyrexia or because of the increasing intrapleural pressure. We know that the more these effusions are aspirated the more cellular they become, and the greater, therefore, the consequent complications. I have seen startlingly good results on odd occasions in the early stages of acute effusions from methylene blue, among other trials, but I know of no specific. We have yet to learn whether para-aminosalicylic acid will prove, if not a specific, at any rate a drug which has an appreciable influence in checking the acute phase of these intense pleural infections. When the acute processes, the rapid reaccumulation of fluid with pressure manifestations, and the pyrexia persist and irrigation with azochloramide has failed, the sooner an air-tight drain is inserted and a thoracoplasty done the better. But this is not always practicable. It is in this connexion that I do want to emphasize that the drainage of a tuberculous empyema does not necessarily mean a permanent sinus. I will give one instance, among several. A youth came to me in 1934 with bilateral disease, more extensive and more active on the right. After a time of rest in bed to stabilize the condition I did an artificial pneumothorax on the right. This produced partial control only and was very soon complicated by a most acute effusion, loaded with tubercle bacilli. I had to aspirate on account both of the continuous high temperature and of the pressure symptoms. The effusion kept recurring with increasing frequency and $I$ was forced to insert an air-tight drain. I kept this in for twelve months as the lung would not re-expand. When it was removed the wound closed immediately, but I had to start aspirating again. Three months later I reinserted an air-tight drain, which I maintained for four months. Again the wound closed within a week, this time without reaccumulation of fluid. Later I induced an artificial pneumothorax on the opposite side. The patient is still alive and doing well.

But it is the intermediate effusions that interest me more. These start usually with a pyrexial attack, but of a shorter duration, and the fluid accumulates slowly yet inexorably. This type of effusion I welcome. The patient has a persistent mild pyrexia and is kept in bed. If pressure symptoms develop, I aspirate air from above the fluid until the pleural cavity is filled with fluid only. Once this state has been reached the temperature subsides. A small aspiration of fluid may be necessary once or twice, and then stability is acquired. From that time on the lung collapse is maintained in a constant state, which is infinitely more efficient that the continued re-expansion and recollapse with an artificial pneumothorax; and the progress of the patient is better. As I keep a periodic check on the intrapleural pressures until I know stability is assured, I have never 
seen a bronchial fistula develop. Later rather than sooner the fluid will start to absorb, and then a change-over to oil can be made.

\section{OleOTHORAX}

This brings me to the subject of oleothorax, where once again I expect to be provocative. Oleothorax is, in my opinion, made too little use of in this country. Whether this is because you don't realize the value of it, or whether through insufficient experience you are prejudiced against it, or whether because, like me, you are lazy and do not sufficiently often bother with it, I don't know. Used wrongly it is most dangerous : used in the right type of case it is of immense worth.

It is not to be used in the presence of adhesions holding out the lung. It is not to be used to exert pressure on a lung which does not respond to an artificial pneumothorax. It is not to be used over a collapsed lung with a tension cavity sticking out of it. On the other hand, it is an ideal method of maintaining collapse of a lung once that collapse has been obtained by satisfactory artificial pneumothorax when stability has been reached; and even more so when, despite an apparently satisfactory collapse, the sputum remains positive. I have already indicated the use of oil when a chronic effusion complicating an artificial pneumothorax is beginning to be absorbed.

An oleothorax is much more efficient than an artificial pneumothorax, as the collapse is constant and the lung is not subject to that to-and-fro expansion and collapse of an artificial pneumothorax. The same applies to the use of oil in an extrapleural pneumothorax. There is no more need to worry about the permanence of the collapse than after a thoracoplasty, and the feeling of wellbeing is as complete without the risks of the major operation or the fear of deformity. Moreover, if you so desire, it is reversible.

One of my early cases was a young woman of 26 with an upper-lobe cavity and a positive sputum. I obtained a perfect selective collapse of the upper lobe: chance, not design. She wanted to marry and live in Kashmir within eighteen months of the induction in August, 1929. How could refills be continued ? I didn't know, so I converted her to an oleothorax. She returned seven years later still perfectly fit, with the upper lobe collapsed as satisfactorily as ever. She needed only $30 \mathrm{c.cm}$. of oil to "top" her up. She has since gone to Jamaica to live there (Plate III $a, b$, and $c$ ).

One absolute essential of a safe oleothorax is that there shall be some slight expansion of the lung during full inspiration: that at least is my feeling. If I have found the lung so compressed that there is not the slightest sign of expansion with full inspiration, I consider the pressure is excessive and I reduce it (Plate IV).

At the beginning of the 1939-45 war I changed over some of my patients from air to oil lest there should be difficulties in refills. All have appreciated the change. Once established I check up the pressures in three months, then in six, and then yearly.

I have used paraffin and olive oil, alone or with gomenol. Mostly I now use olive oil only, but use this with gomenol when replacing an effusion. I have also used olive oil and gomenol after a mixed infection of the pleufal cavity once this infection has been checked by sulphathiazole and penicillin.

Crimm and others have used peanut oil and cod liver oil in the treatment of acute tuberculous empyemata. These oils are more irritating than olive oil : they inhibit to a slight extent the growth of the tubercle bacilli by physical action, but are mainly efficacious in that they produce an exudate which seals over the foci of infection on the visceral pleura and produce an obliterative pleurisy. These authors wisely insist that periodic removal of pus or fluid in order to maintain a negative pressure is mandatory. They have used these irritant oils even when the pleural cavity has been secondarily infected, but after irrigation with sulphathiazole.

There is this difference between Crimm and myself: my endeavour has been to maintain the collapse of the lung, Crimm to re-expand it.

The advantage of oil over air is, I believe, on a par with the better response of a thoracoplasty over an artificial pneumothorax. As Maier says, ${ }^{*}$ discussing the treatment of tension cavities: "The immobility of the thoracic cage with practical elimination of lung motion which follows extensive thoracoplasty may be an important factor. Because of the lack of mobility of the lung and bronchial tree under thoracoplasty, there may be a greater tendency to more complete blockage of the bronchus."

\section{Phrenic Crusih}

I am not going to say much about phrenic crush. I suppose I do one to-day to every 50 crushes or evulsions I used to do 15 to 20 years ago, when a spirit of optimism and an attempt to evaluate its uses were my dominant idea. It has its uses, but they are limited. It may help an artificial pneumothorax when the lung is well collapsed against the mediastinum but is drawn taut between indivisible

*Amer. Rev. Tuberc., 1945, 51, 1. 
apical and basal adhesions. Sometimes it is a valuable adjunct to rest in bed for a small, thinwalled cavity below the clavicle. I do not think it has the slightest value in moth-eathen apical cavities, nor in true apical cavities, nor if the cavity has a thick wall or is a tension cavity: though very rarely one does see a startling result. Undoubtedly it will relieve the nagging pain sometimes associated with an old diaphragmatic pleurisy. Probably one of its main advantages is in association with pneumoperitoneum, especially in lower-lobe cavities. Always there is the fear, if a thoracoplasty may eventuate, that the diaphragm will not recover. There is one point I have noticed in several cases. If a crush has been done and is beneficial in closing a cavity, and later the cavity reopens as the diaphragm recovers its function, a second crush is usually ineffectual-not in paralysing the dome, but in reasserting its influence on the cavity. This, however, may not be cause and effect.

\section{PNEUMOPERITONEUM}

On the question of pneumoperitoneum I am going to say less, because I know less. There are some who are real enthusiasts for this line of treatment. Probably their choice of case or technique is better than mine. As with all forms of treatment, I have had most pleasing results, but also too many disappointments. I think it undoubtedly has a value in bilateral cases, especially when artificial pneumothorax is not possible. It may occasionally help to stabilize the disease so that later some form of major surgery is permissible. Mallick and others, from their experience in India, suggest that the real merit of pneumoperitoneum "lies in its particular applicability to advanced bilateral cases in a country like India where the early detection ... of the disease are yet in infancy." In bilateral cases I prefer to start with the pneumoperitoneum and to reserve the phrenic crush for that side which is seen later to need the more help. Pneumoperitoneum has also a value in arresting a basal extension so that a more limited thoracoplasty is eventually possible. It is indicated also when fluid is complicating an artificial pneumothorax on one side and there is spread in the contralateral lung: then, especially if the disease is below the apex, the pneumoperitoneum is preferable to an artificial pneumothorax, because of the danger of bilateral complications by effusion.

There is one point in connexion with pneumoperitoneum I would call attention to, and that is that this treatment has a most distinct tendency to bring into prominence in women pelvic disorders, which up till the introduction of air had been unsuspected or were responsible for minor symptoms only.

\section{CAVITIES OF THE LOWER LOBE}

Cavities of the lower lobe, when disease elsewhere is minimal, need special consideration. Here again I would emphasize that whether one is a pneumoperitoneal addict or a thoracoplasty fan, or a cavernostomy optimist, there is no single line of treatment applicable to all cases. One reason is that the cavity in the apex of the lower lobe, that is, associated with the dorsal-lobe bronchus, is less amenable than a cavity associated with the posterior basic bronchus. The cavity in the apex of the lower lobe is closely confined between a, usually, thickened interlobar septum and the posterior thoracic wall. By its enlargement it collapses and compresses all the surrounding available lung substance ; and, by its proximity to the chest wall, it usually becomes firmly adherent to it. The basal branch cavities have more available lung tissue around them and are less often adherent. Tomograms as well as lateral films are invaluable as a guide to the probable fixation of the cavity wall to the chest.

It is the cavities in the basal segments of the lower lobe which are most likely to respond to pneumoperitoneum associated with a phrenic crush. This line of treatment is also worth trying in those cavities situated close to the lung root. Edwards and Logan rightly emphasize that for any rise of the dome to be beneficial the disease should be "soft," any cavity thin-walled and surrounded by comparatively healthy lung tissue.

One further difficulty of collapsing dorsal-lobe cavities by a pneumoperitoneum is that the main rise of the dome is of the central and anterior segment of the muscle. Whilst on a posteroanterior film there is, apparently, an excellent rise, a lateral, or better a lateral tomogram, shows how inadequate the rise of the posterior segment may be (Plate $\mathrm{Va}$ ). In such cases I have succeeded in obtaining an efficient collapse by supplementing the pneumoperitoneum by a localized rib resection over the cavity, including a rib above and below, and depressing this area by a fitted pad.

When the cavity has been a tension cavity, I have even put in a Monaldi drain; then, when the cavity was reduced or apparently obliterated, I have excised the track, oversewn the opening into the lung, oversewn this again by muscle over 
a packing of promine jelly, and then done the local rib resection.

I must admit, however, that since I did my first basal thoracoplasty in 1926, resecting ribs from below upwards to the third, and sometimes even the anterior end of the third, this method seems to have given me my best results.

I have never done a cavernostomy, and, though once or twice tempted, I hope I never shall.

The possible use of polythene packs, to which I shall be referring later, has most definitely to be considered in the future in the treatment of these basal cavities.

\section{Tension Cavities}

Fifteen to twenty years ago the term "tension cavity" hardly came into the tuberculosis vocabulary. Now it is with us all the time. I do not think this is entirely the result of our greater understanding: some part of it unquestionably. But I do think, too, that the character of pulmonary tuberculosis is changing. Just as we see less of the acute miliary form of the disease, so are we seeing more lungs with tension cavities. In the same way, and more recently even, tracheo-bronchial tuberculosis has come to the fore. I wonder, when I read for instance Judd's recent paper on five hundred cases of tuberculosis bronchoscoped, with a positive visible finding in 37 per cent, whether this condition is commoner in some countries than in others. I am now, as a routine, bronchoscoping all my patients prior to a thoracoplasty and also those cases treated by artificial pneumothorax which show localized collapse. Maybe I am not so skilled in noting the intrabronchial changes, but so far my findings are considerably less. There can be no doubt that a localized change which is out of sight in the smaller bronchioles must frequently be present and can only be guessed at by its consequences.

The presence of intrabronchial tuberculosis does influence the line of treatment adopted: it is often a contraindication to an artificial pneumothorax, or to the continuance of one when there is associated collapse. It is usually an indication for a thoracoplasty: it may, however, be responsible for residual, uncollapsed cavities despite a good collapse of the lung. It may make resection inadvisable, unless the intrabronchial tuberculosis has passed the active and reached the stenotic stage, when it can be an indication for resection.

\section{THORACOPLASTY}

What a contentious subject! What years of illusion and of disillusionment; of constant endeavour and frustration! The fateful years were 1909-13. Before that de Cerenville, Quincke, Spengler, Turban, and then Friedrich, at the instigation of Brauer-all honour to these men-had been making attempts but without great success. Then into the field came Wilms and Sauerbruch with their planned operations which may be said to have launched thoracoplasty into the realms of thoracic surgery. There was a certain similarity in the general principles of both these surgeons. Both realized the necessity of resecting the posterior ends of the ribs back to the transverse processes: this had already been insisted on by Gourdet as long before as 1895 : both also insisted on the importance of removing the first rib. They differed, however, in that Wilms planned the "Pfeilerresection" operation, in which he resected short lengths of the first eight, nine, or ten ribs and, at a later stage, the first five to six costal cartilages, leaving thereby his " column" of mobilized ribs between these two resections.

Sauerbruch, by 1913, had fully planned his " paravertebral extrapleural thoracoplasty," which consisted of the posterior resection only of the first down to the tenth and even the eleventh ribs. $\mathrm{He}$ it was who recognized that the pliability of the costal cartilages allowed of collapse (1) by the approximation of the cut end of the ribs towards the spine, (2) by the dropping downwards of this posterior end of the ribs, and (3), most important of all, by the "bucket-handle" mediastinal approximation of the ribs.

In 1912 and 1913 I used the Wilms technique, but in the anterior stage my resection extended to and included the costal margin. The posterior ten-rib resection was done in one stage and the anterior resection was done a fortnight later. As you can imagine, the great anxiety was control of paradoxical breathing. At that time no one was allowed to touch the many-tailed bandage except myself. In 1915 I omitted the anterior resection but still did the posterior resection in one stage.

These early thoracoplasty results, provided one resected the ribs well back, were most satisfactory in the collapse obtained, and equal to many of the modern thoracoplasties. But, as I have indicated, in those days the tension cavities were less in evidence and the choice of case more conservative.

From 1916 to 1922 I did no major chest surgery, but in 1922 I started again and did four thoracoplasties-all one-stage. Of these patients, one died a year later from tuberculous enteritis. The other three were all alive in 1945, when one died of influenza and pneumonia.

Then John Alexander stayed with me and urged the advisability of resecting greater lengths of ribs 
in multiple stages, and also the transverse processes. As a result many of my thoracoplasty collapses from 1931 to 1935 were so indifferent and even bad that I was tempted to abandon operating. I went to America in 1935, and found their results no better. It was on my return that I suddenly realized I had forgotten "the lesson of the master" and my own teachings. The longer resection of the ribs, below the third, so reduces the leverage on the costal cartilages that the " bucket-handle" drop of the ribs was completely interfered with. I remodelled my operation, removing the whole first and second ribs and 10 to $12 \mathrm{~cm}$. only of the rest. In addition I resected the transverse processes to abolish the costotransverse process-vertebral gutter. The operation was done in two, sometimes three, stages.

There has been a great deal said against the removal of the transverse processes on the grounds of deformity (Plate $\mathrm{Vb}$ ). I often wonder how much of that talk is careless repetition of some emphatic statement made by one unversed in physiotherapy, till it has assumed the garb of truth. I know that for years one of my colleagues and I have operated on alternate cases: I with the technique described above: he leaving the transverse processes and favouring the Semb strip. I maintain that my cases showed no greater deformity than his; nor than those cases which have come my way and which have been operated on by other thoracic surgeons.

Of late years I find I have become once again progressively interested in the removal of the first to the fourth costal cartilages inclusive as a preliminary to posterior thoracoplasty (Plate VI $a$ ): thus, after some thirty-odd years, coming back full circle to the Wilms type of operation. I am even more interested to find that other surgeons also are using this technique.

My personal reasons for removing the costal cartilages are not only to afford a safe passage for a Monaldi drain but because I recognize that the costal cartilages will not always allow all the torsion that is required, especially for the collapse of large tension cavities. Further, as one operates on older people than formerly, one has to recognize the progressive increase in rigidity of these cartilages with advancing years.

There is no doubt that when faced with a large tension cavity the combination of an anterior stage with the insertion of a Monaldi drain, which is then maintained until the posterior stages have been carried out, is a great help towards a satisfactory collapse.

But meanwhile the world of thoracic surgeons had become rocked by the advent of the Semb strip. It became the vogue and has, to a great extent, remained so, because, so I was told, it was solving so many of the problems. I remained an isolationist: I have never been convinced that this modification produces the results claimed. Nor, I somewhat surmise, are you all as completely convinced these days.

There are two different principles employed in thoracoplasty. The one is the old-fashioned direct collapse by removing ribs and possibly transverse processes. This, for want of a better name, might be called the contra-mediastinal collapse. Some call it a compression collapse, but that it not quite a true description. The other method is the relaxation collapse, which includes the Semb strip. It is in some ways on a par with the stage one extrapleural and stage two thoracoplasty operation practised by Reid,* except that in the Semb the dangers of disseminating tuberculous infection are less.

In my opinion the essentials of the contramediastinal collapse are that the costo-vertebral gutter must be abolished by removal of the transverse processes, and that the mediastinum is comparatively fixed. 'For large cavities, and in patients with any tendency to ossification of the costal cartilages, an anterior stage with or without Monaldi drainage is advisable.

Of late years I, as so many others, have been doing multiple stage operations when an extensive collapse is indicated. This has the advantage of producing less shock and less danger from paradoxical breathing. Yet $I$ have a strong feeling that the resulting collapse from a two-stage ten-rib thoracoplasty is better than when the operation is done in three stages. Even I would not have the courage to-day to go back to the one-stage ten-rib operation. (Plate VI $b$ and Plates VII and VIII.)

I am sure that the use of weights and of properly applied harness does greatly encourage the torsion of the costal cartilages and the bucket-handle collapse of the ribs. Moreover, it helps to maintain the collapse until the chest wall is set in its new position by regeneration of the ribs.

When relaxation is aimed at, it is essential that there shall be relaxation of the whole of that area of lung containing the cavity or cavities: and that there shall be no tension bands of pleural attachment holding out that area of lung. Inevitably with relaxation of the apex, this and the cavity tend to drop and the relaxation of lateral tension supports must necessarily be continued downwards 


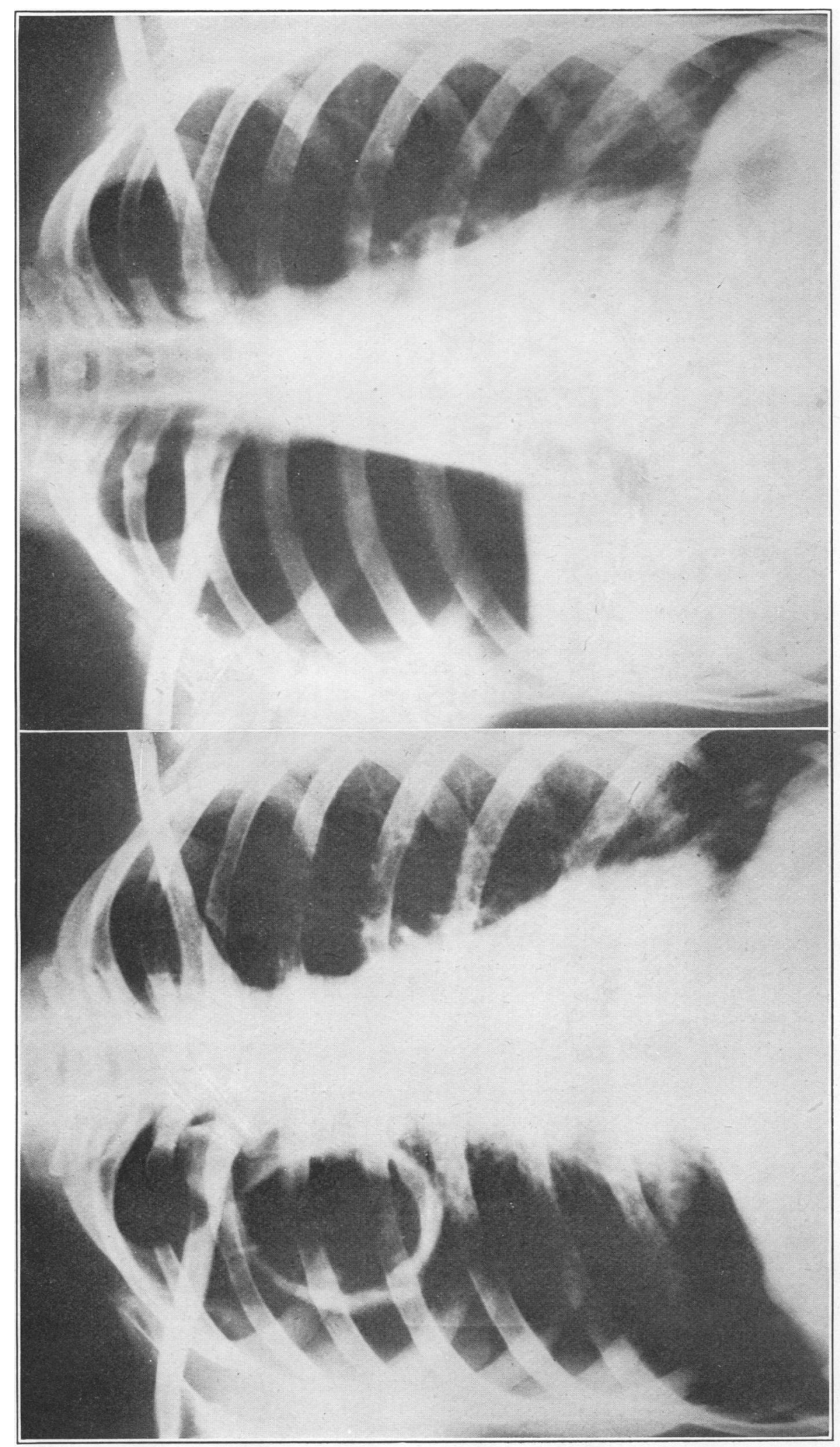

E

궁

F

蛋

อ

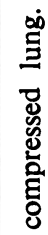

-

을

恶

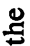

¿

苛

วิษ

ซु

马ु

응

3

है원

卷

4

.05

(동ำ

도ำ

몸

章

高

官 


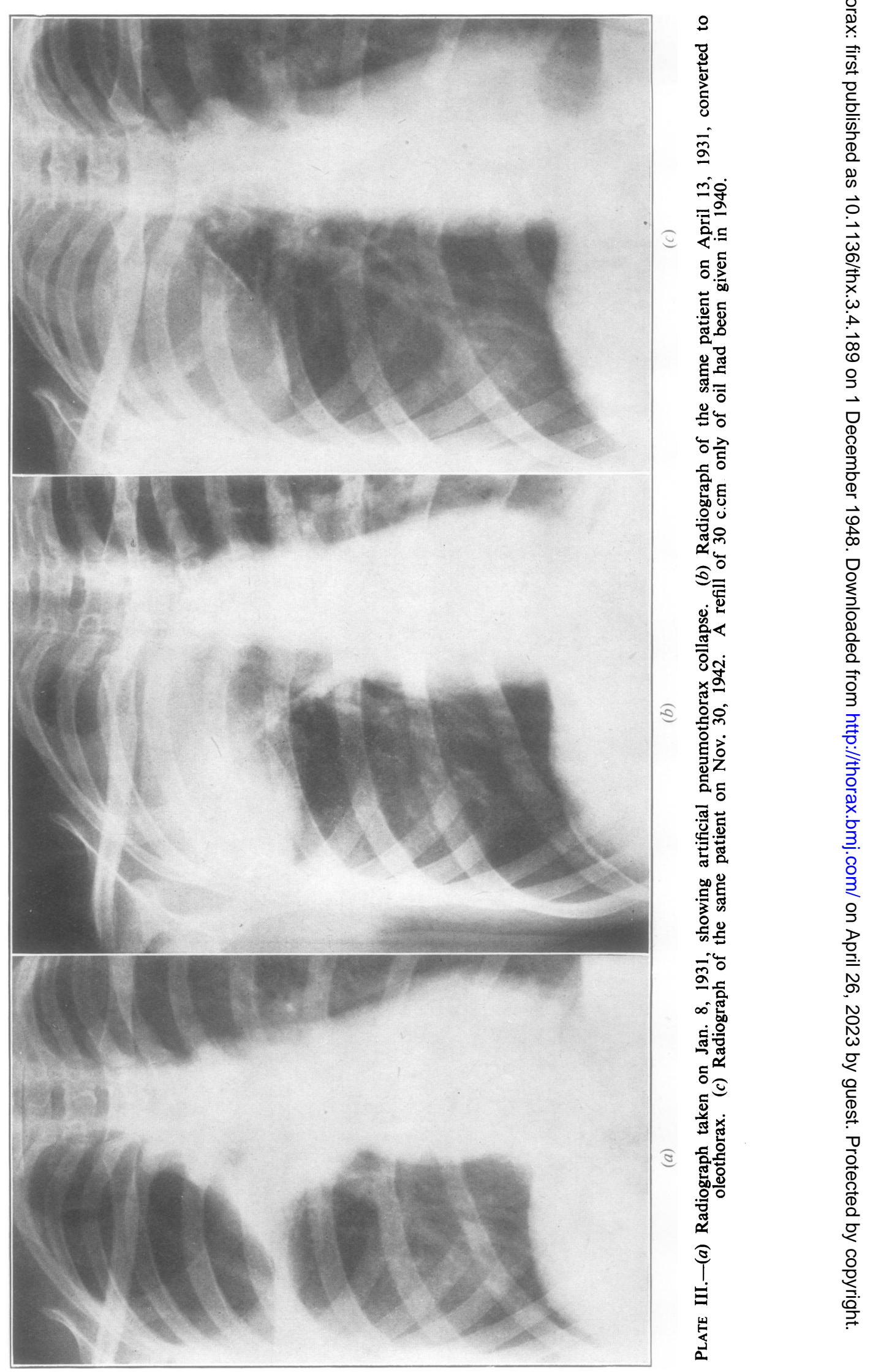




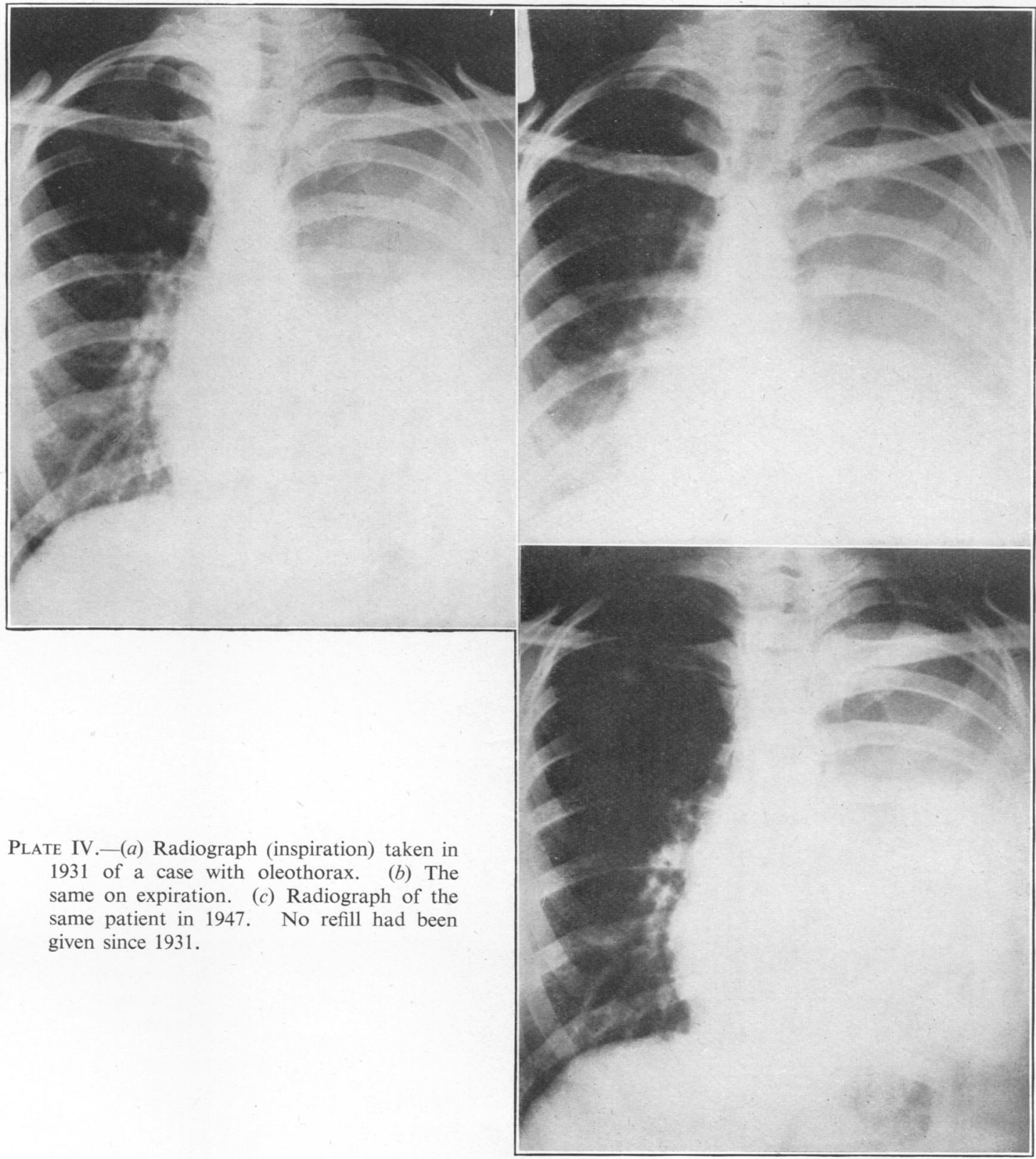

(c) 

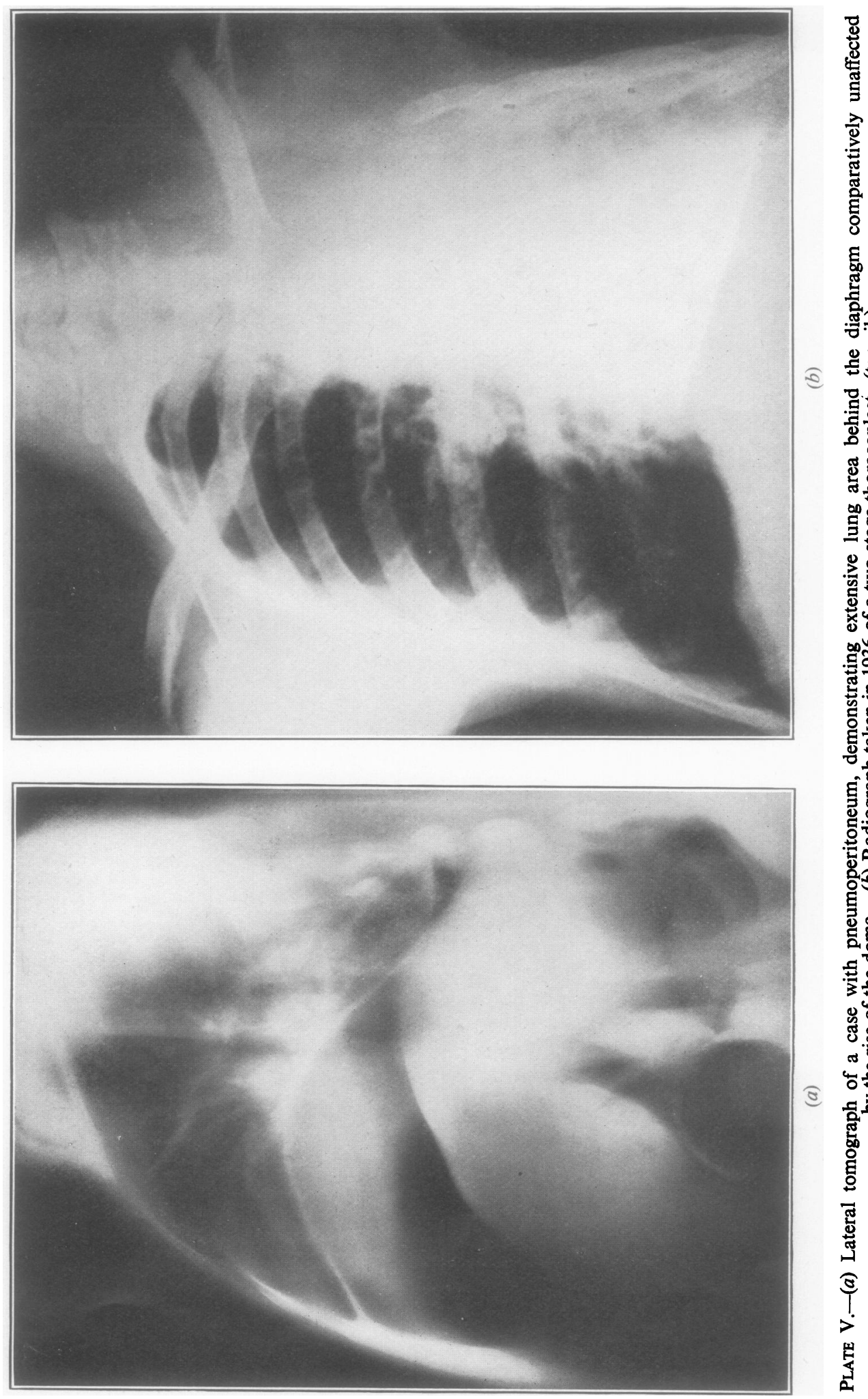

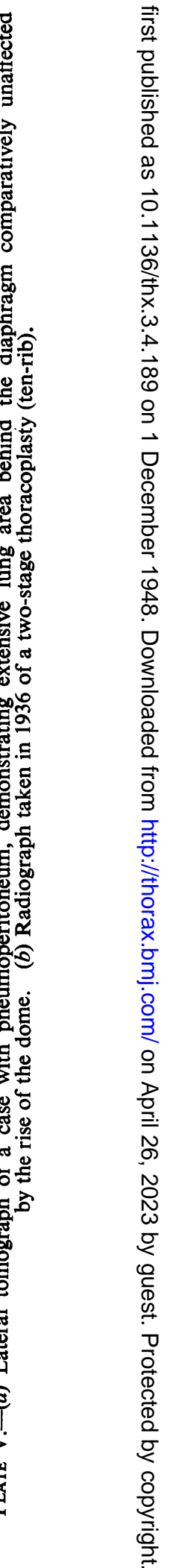




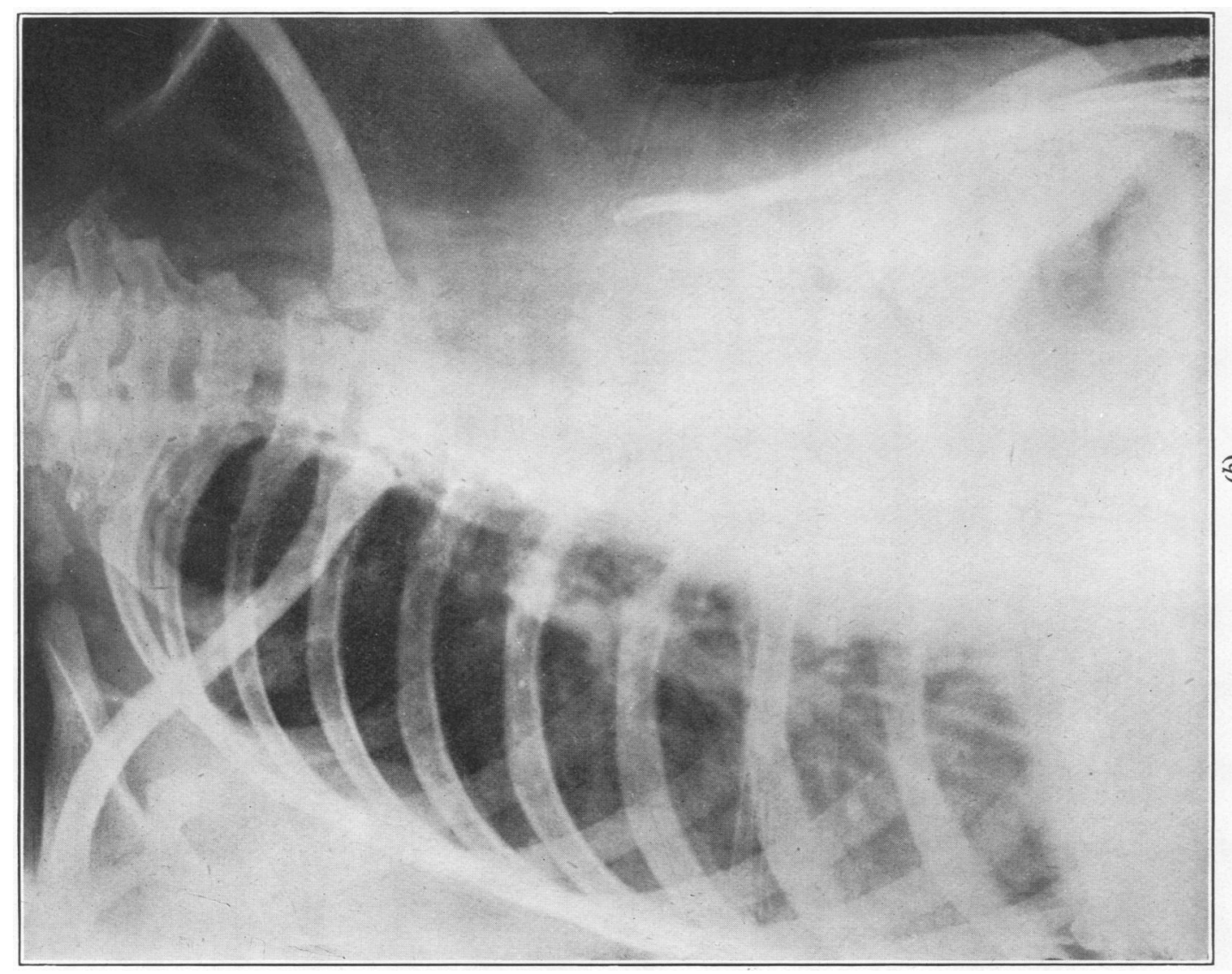

2
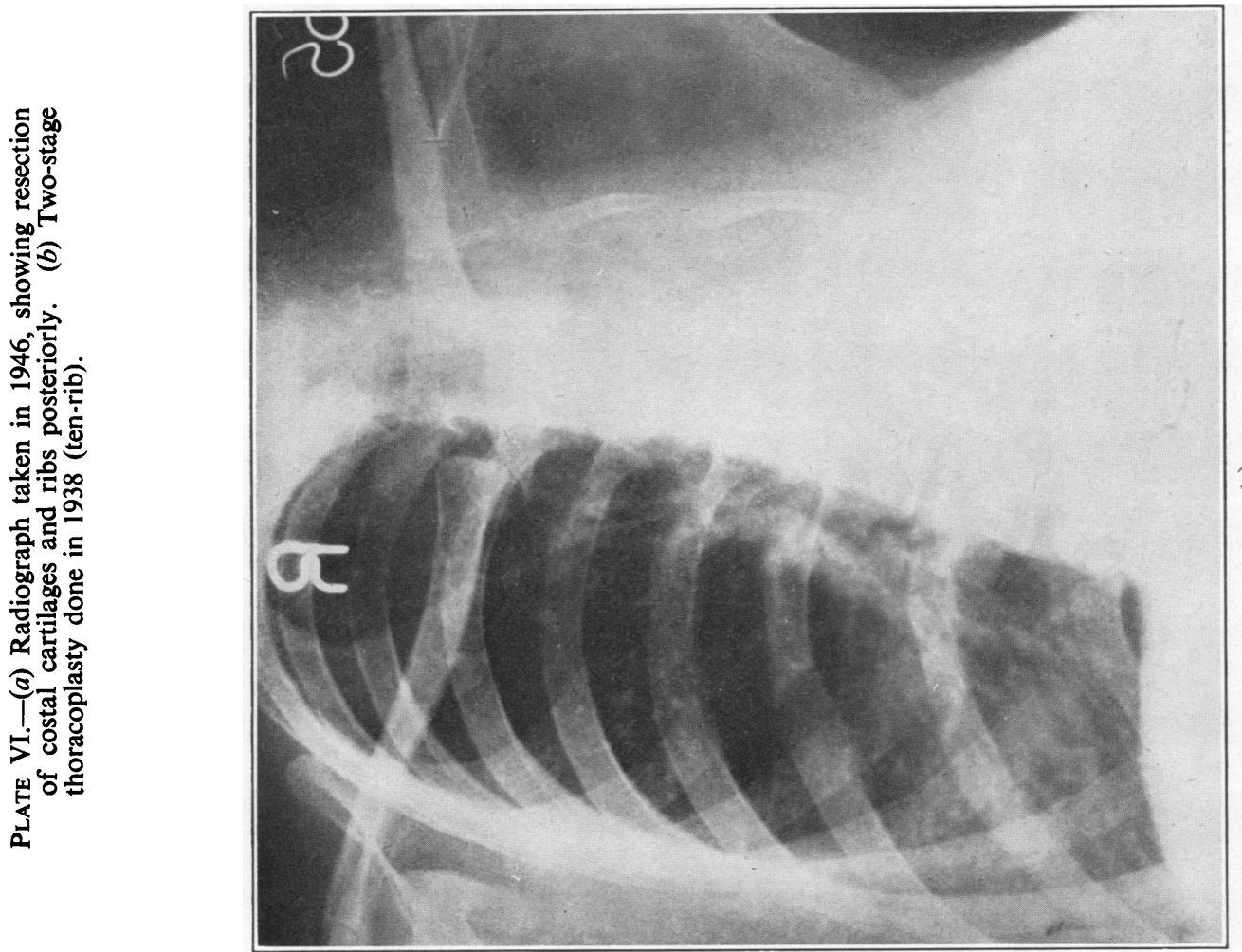

(8) 


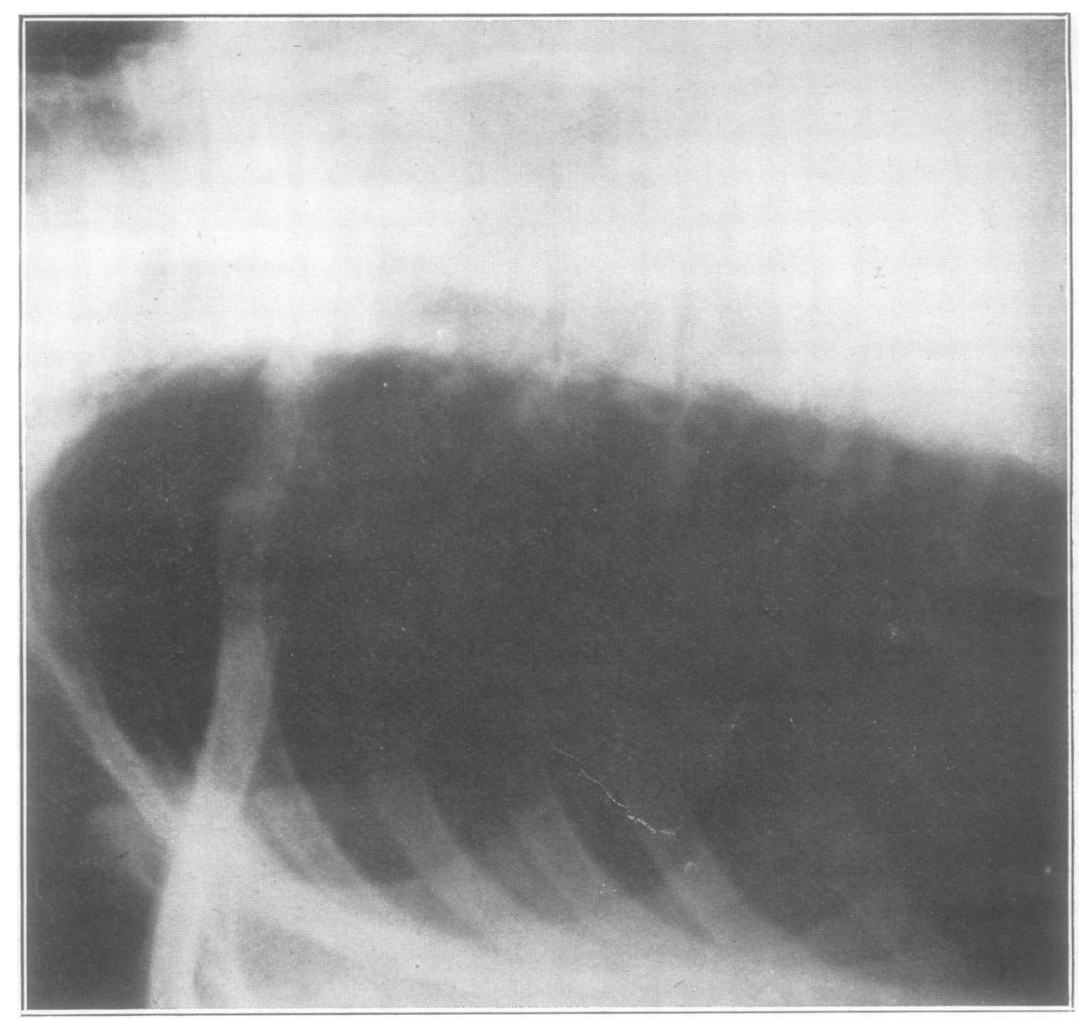

号

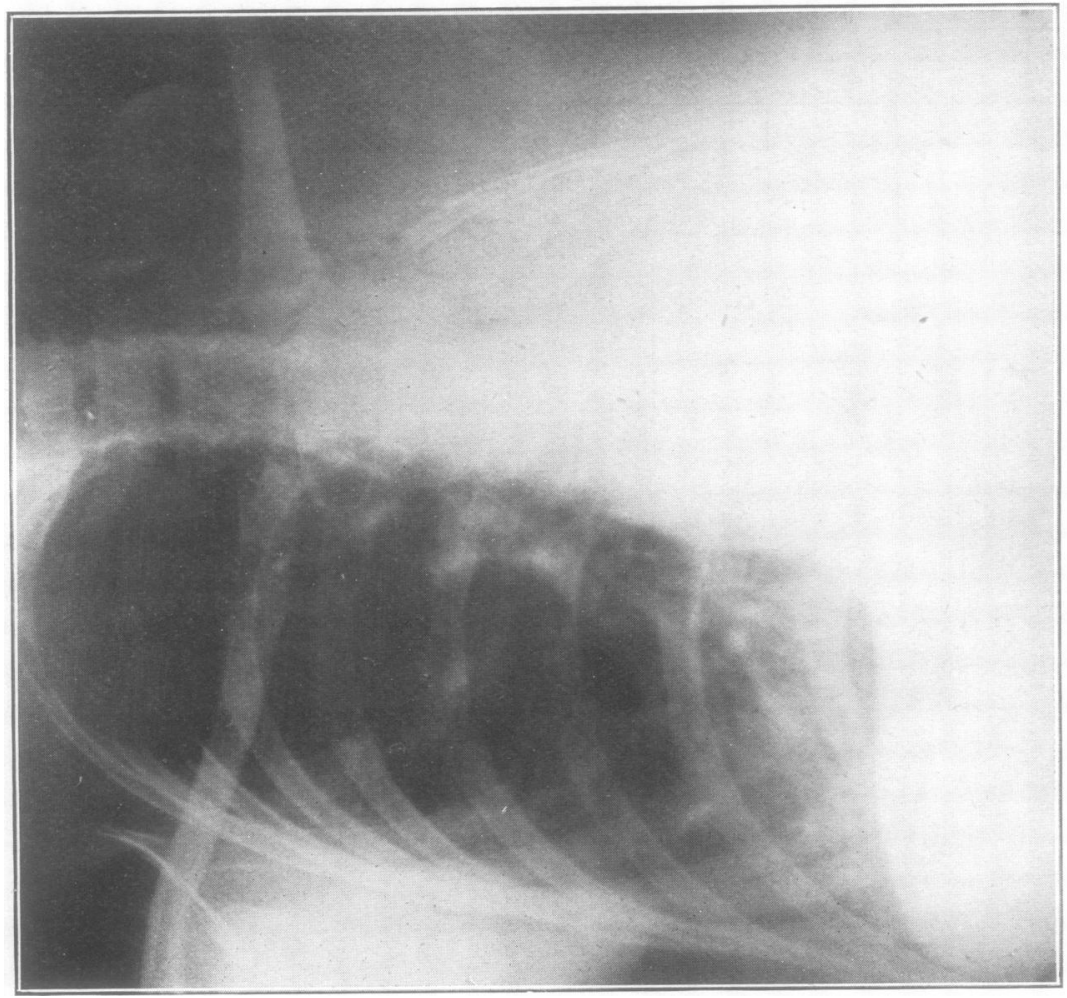




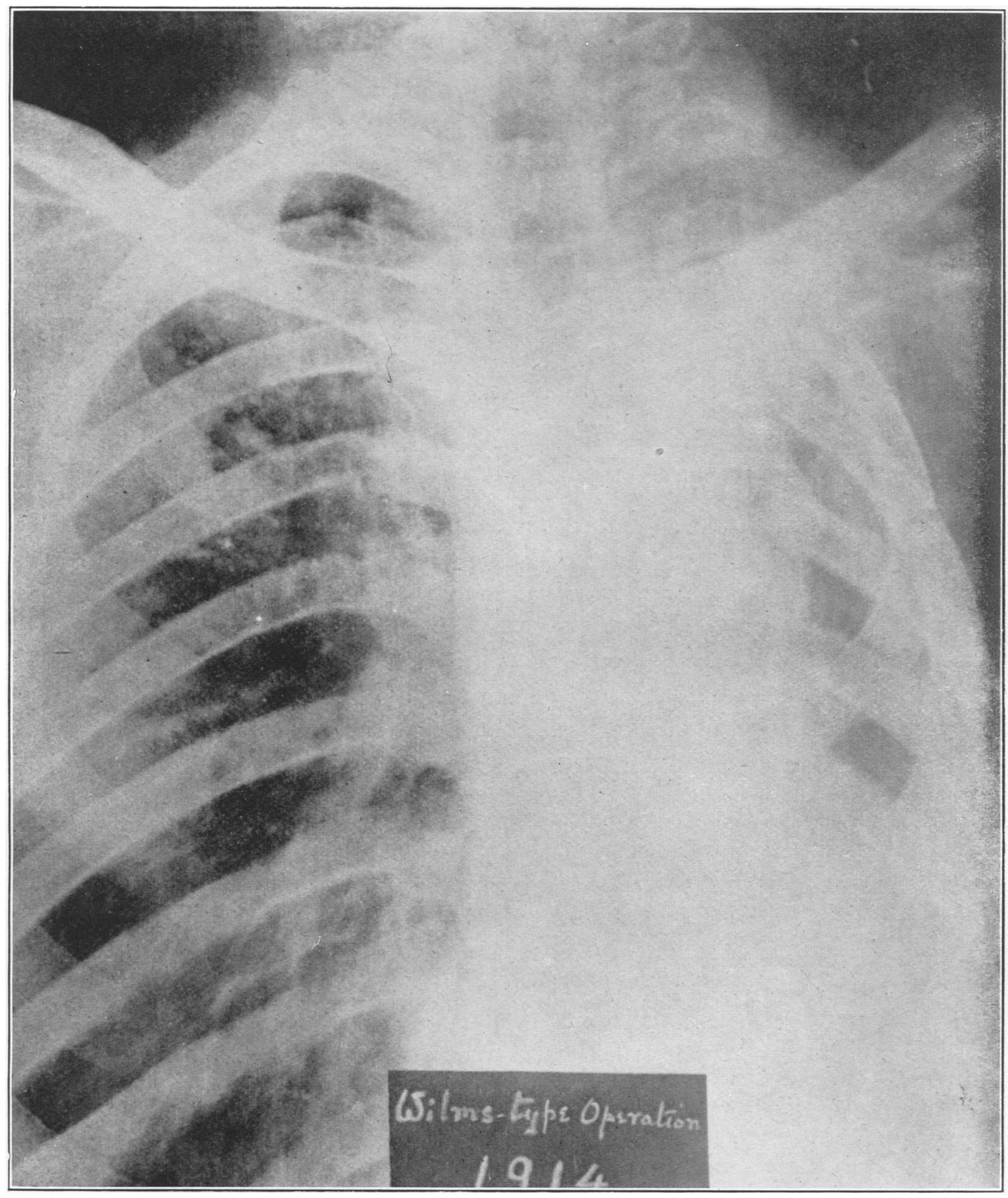

Plate VIII.-Wilm's type thoracoplasty (1914). 


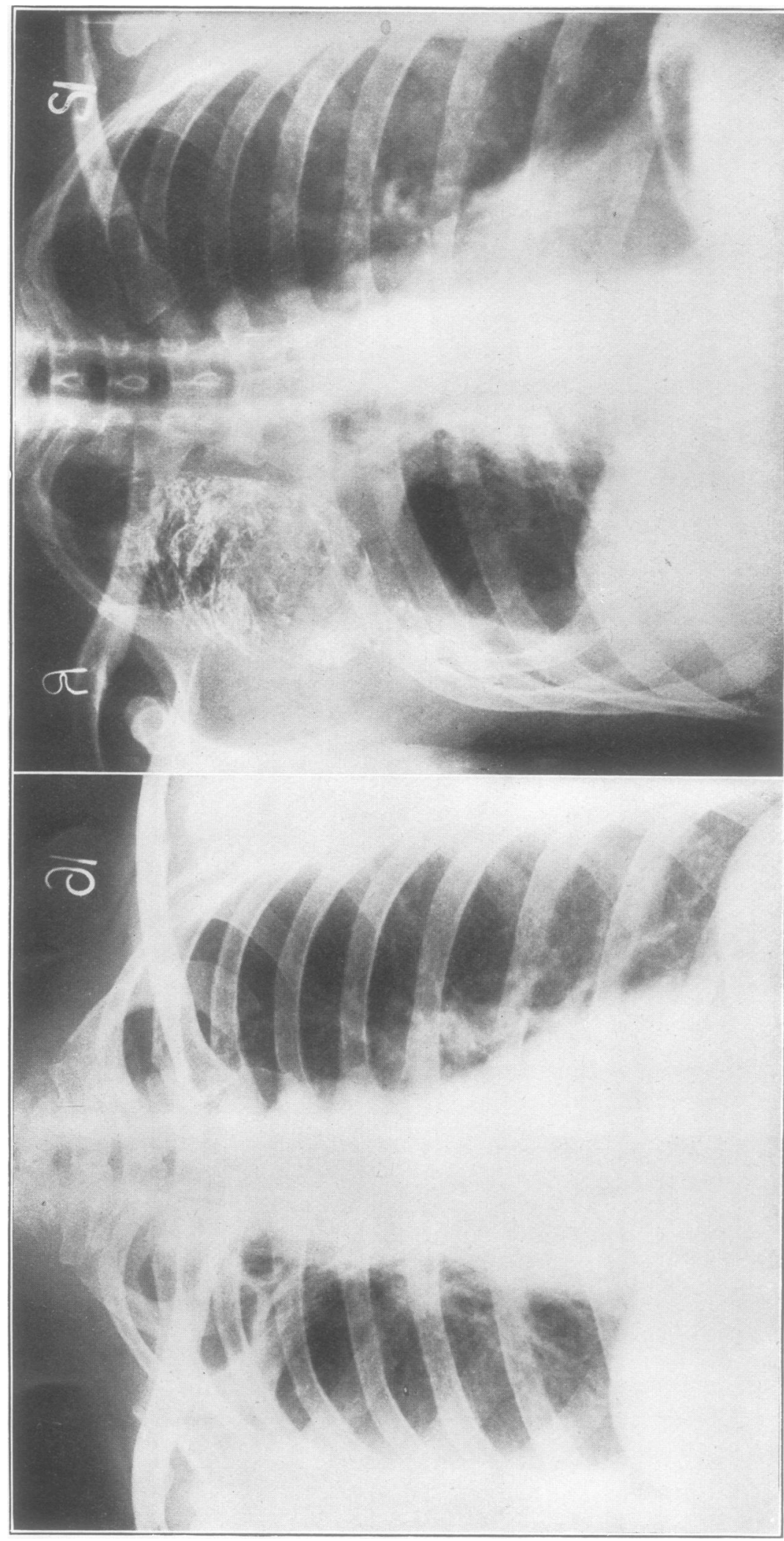

(2)

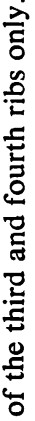

.气̊็

売

ชึ

.

卷

플

5

용

ช

I

a

离

울

㺼

$\pi$

ริ

동

()

.

莡

\%

فํ.

?

战

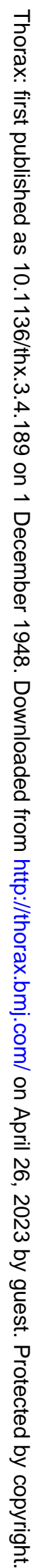




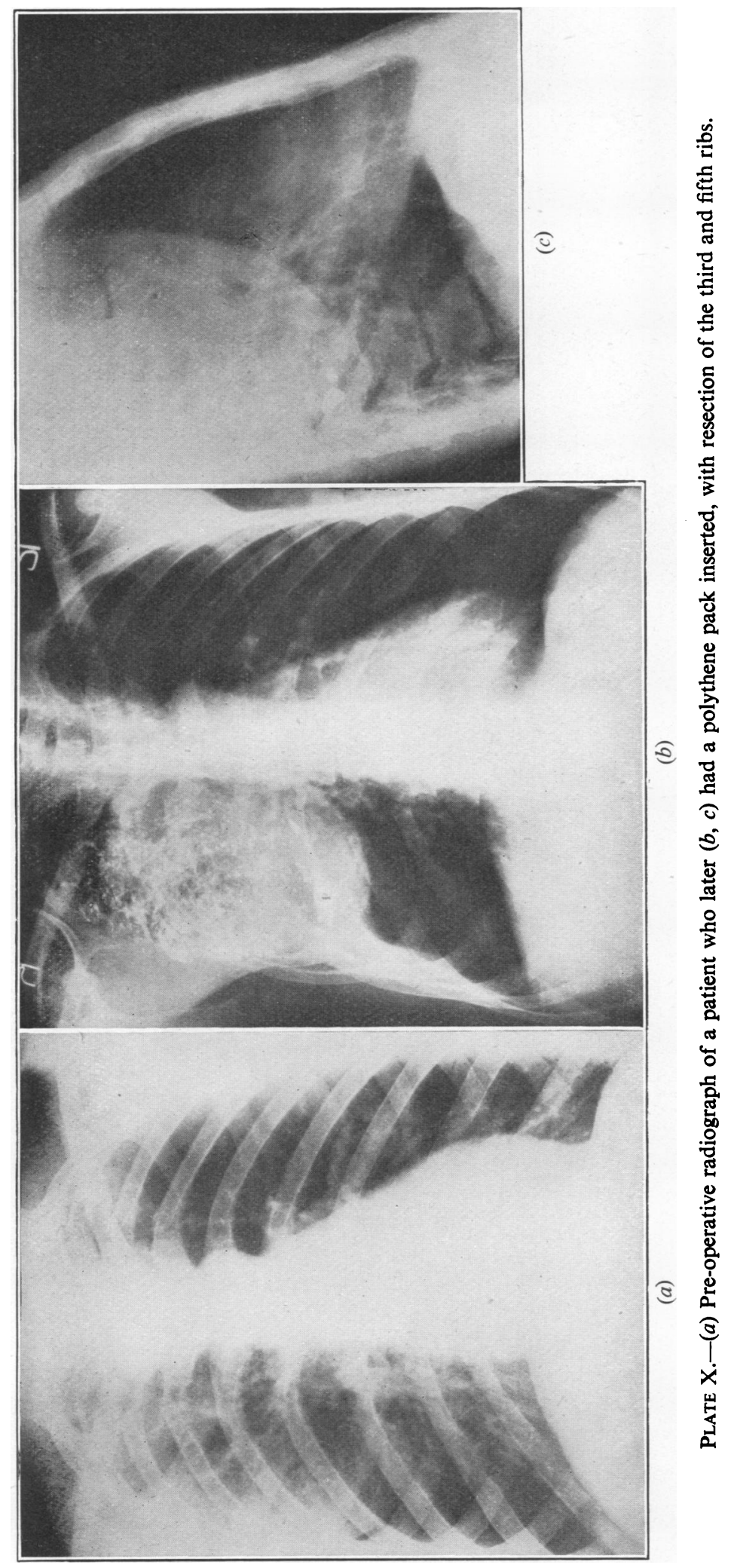

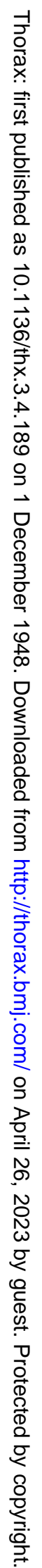




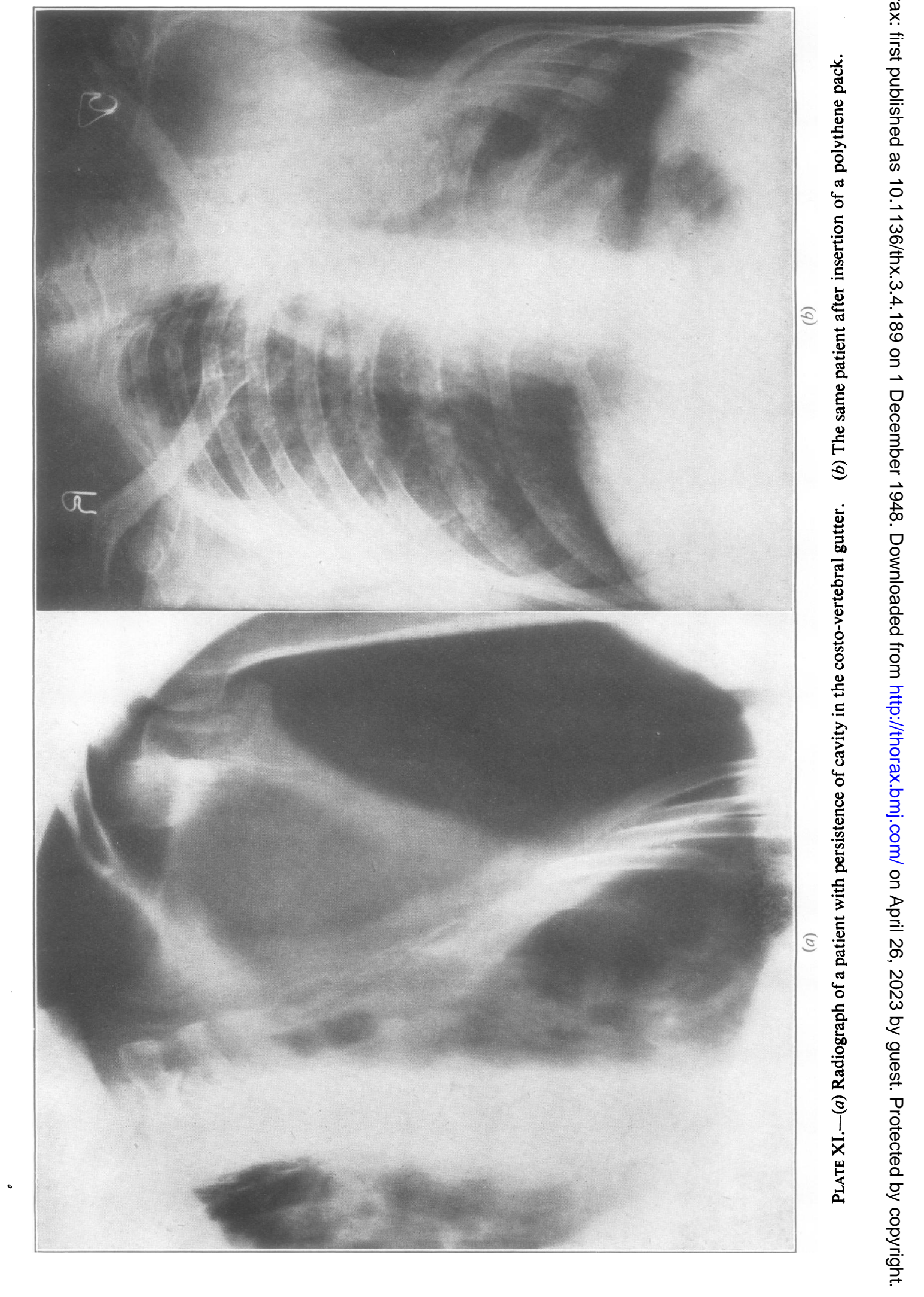




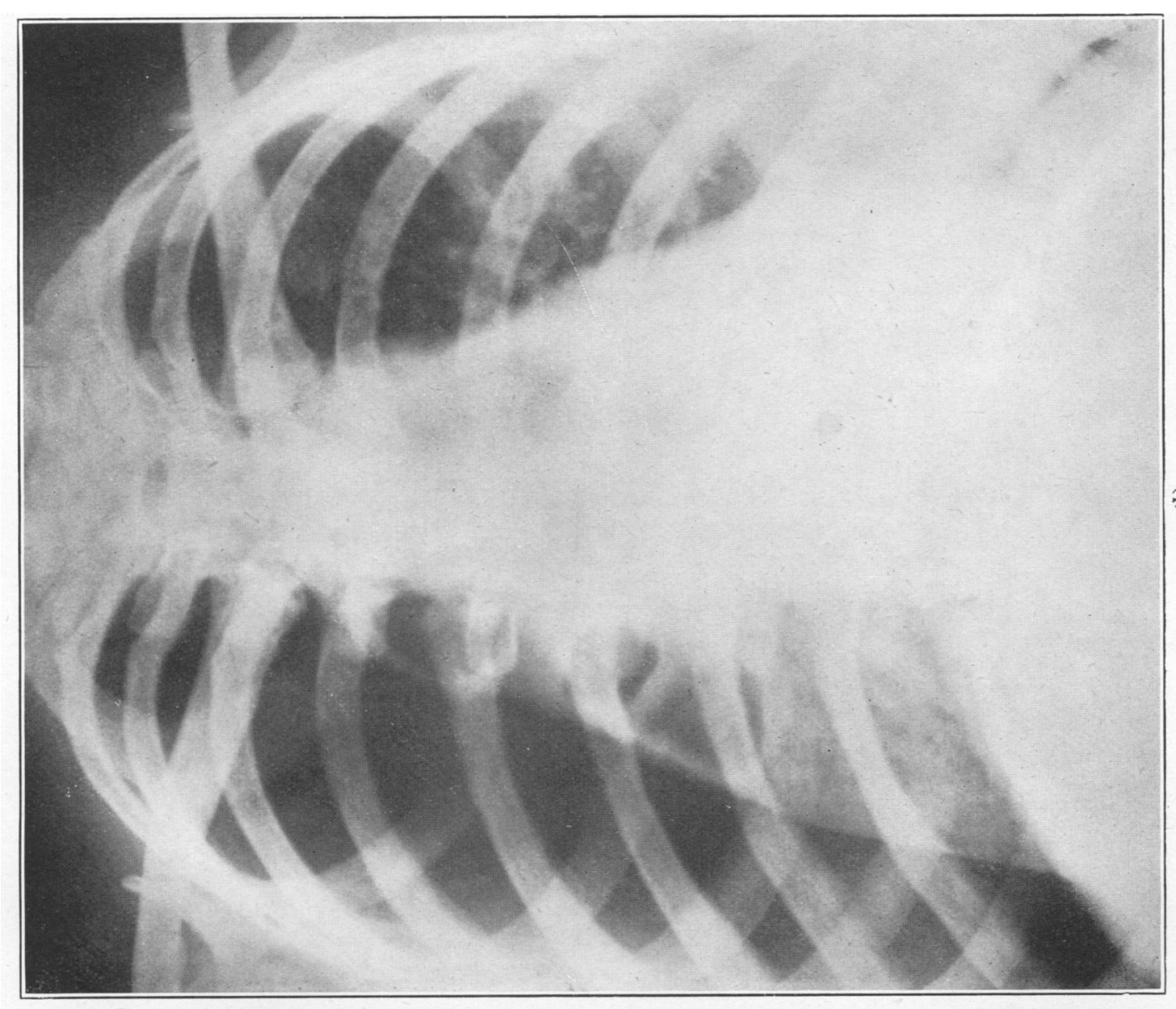



离

ลี

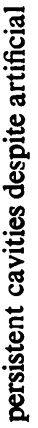

듬.

옹

온

氶

ह

ㅇํㅇ

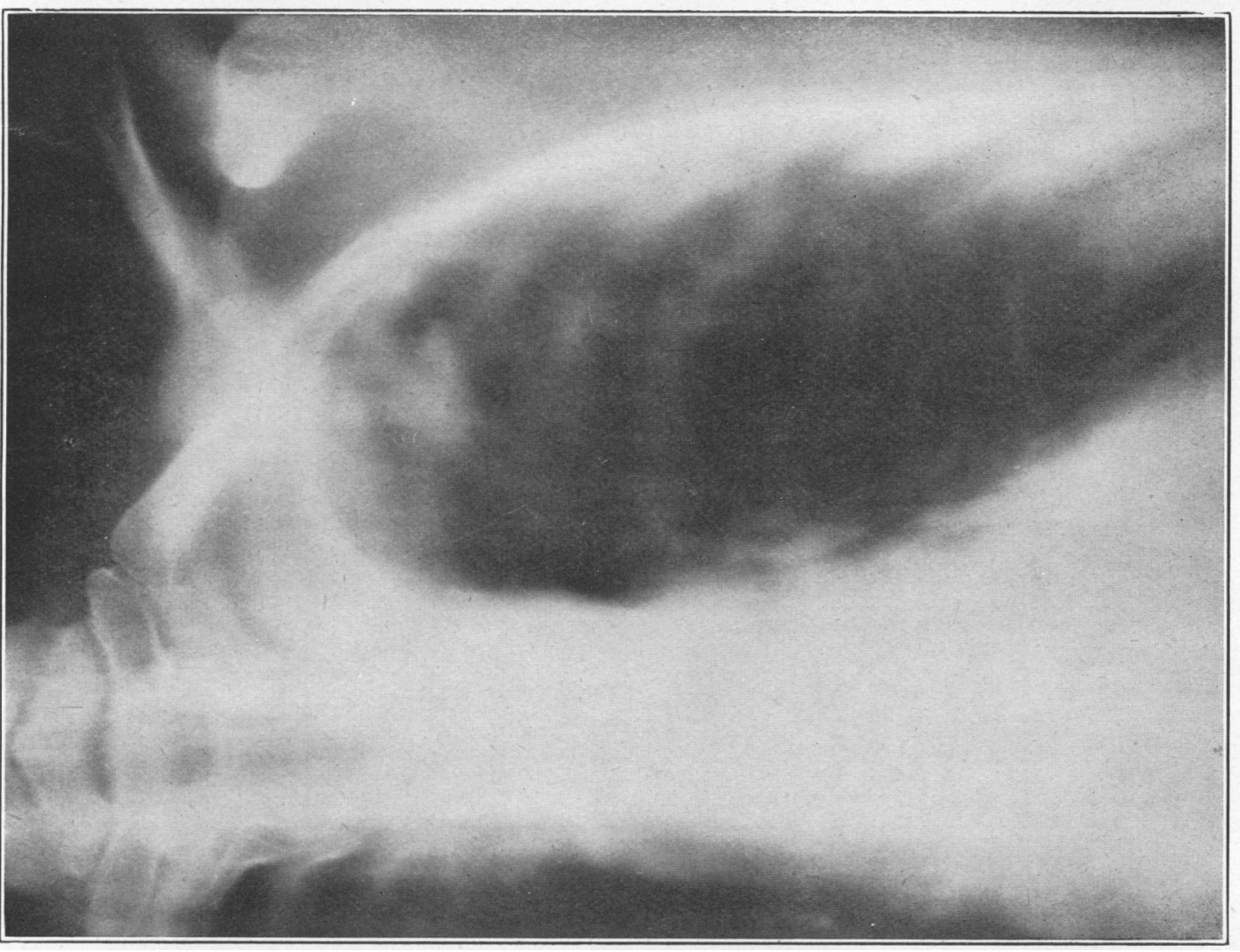




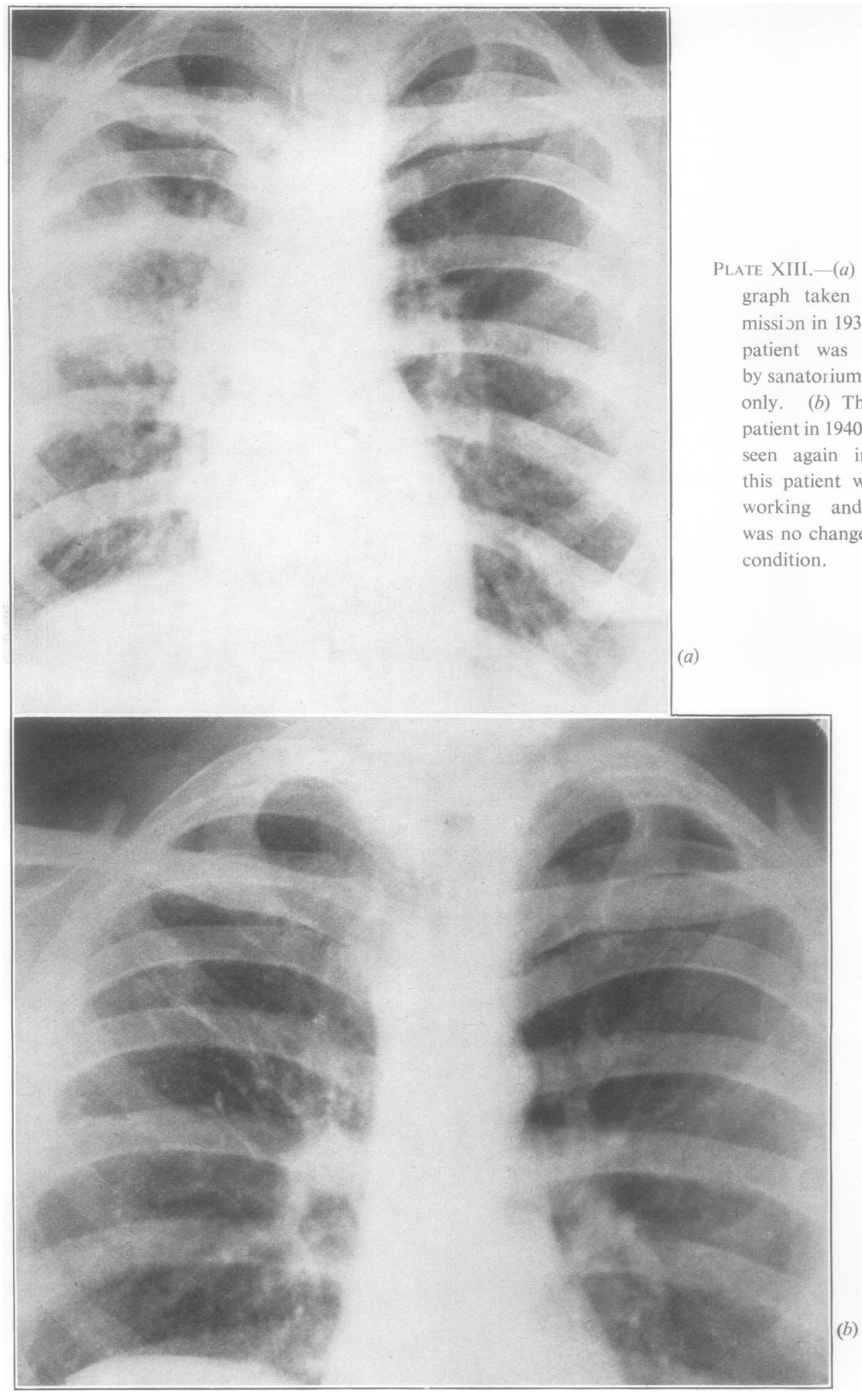


for a considerable distance. In the case of apical cavities situated close to the mediastinum, sufficient relaxation is obtained by a strip to the level of the hilum ; but when the cavity occupies most of the apex, or is more laterally situated and below the level of the clavicle, the extent of strip necessary becomes considerable, and even then not always effective, as the cavity has dropped into the midzone of the hemithorax where it is less easily collapsed, or into the costo-vertebral gutter.

There is yet another problem, however, which is much more devastating to the success of either method, especially for apical thoracoplasties: that problem is how, having obtained the desired collapse, to maintain it. So far as I can see, whatever the method used there is the same tendency, about ten to fourteen days after the operation-as the blood and serum are absorbedfor the lung gradually to re-expand. The amount varies, and pre-existing cavities may or may not reopen. The extent of this process is unpredictable.

It is to overcome this that muscle flaps, bone flaps, and such methods have been tried: it is to the same end that an extrapleural may be done as a preliminary, and then later the thoracoplasty.

None of these attempts have been in my opinion efficacious, and I was therefore particularly interested in the use of lucite balls, as described by Wilson and others. Apart from a natural hesitancy to the use of foreign substances, I did not like the idea of leaving hard, unresilient balls pushed against the vessels and nerves and the diseased lung.

Polythene Sheeting.-In pursuance of the general idea, however, I had the good fortune to meet and to have the generous help of Dr. Wevill, of Imperial Chemical Industries, and of Mr. Swallow and Mr. Holt, of I.C.I. plastics. It was they who suggested strips of polythene sheeting. I admit that at first the idea did not appeal to me; but after they had shown me the sheeting and I had found it to be soft, pliable, and to possess an elastic resilience, and when further it was put to me that the strips could be used in sealed polythene bags, the idea became possessive. Polythene has the same innocuous, non-irritating properties as polymethyl-methacrylate, that is, lucite. It can be sterilized by boiling. After various experiments the packs were made and ready for use.

Meanwhile it had become obvious that the operation of thoracoplasty should be replanned with the use of these packs and that the extensive rib resection was no longer necessary. These new general principles were worked out with my registrar, Mr. Leslie Temple.

For my first operation, which was done three months ago, I chose a patient who had a tension cavity in the right upper lobe, and who would normally have required a thoracoplasty of at least five ribs with transverse processes of third, fourth, and fifth vertebrae (Plate IXa). In this case $I$ resected some $14 \mathrm{~cm}$. of the third and fourth ribs, separated the intercostal attachments to the second rib, and stripped the periosteum off the undersurface of the rib as a continuous sheet with the muscle bundles. I treated the first rib in like manner, and then the fifth rib. The intercostal bundles, including the vessels and nerves, were divided close to their vertebral ends. This allowed the lung with its covering of intercostal muscle and periosteum to collapse against the mediastinum and anterior part of the thorax.

Into the hollow thus formed the pack was inserted, being tucked well up into the apex under the first and second ribs and under the fifth rib. The divided skeletal muscles were then sewn over the pack and the wound closed in the usual way (Plate IX $b$ ).

It is interesting to notice that there is no radiological evidence of any blood or effusion around the pack in this case, though there is some in others, and that the appearance of the pack and lung is the same on the day after the operation and three months later. Following this I have done some further apical thoracoplastics, as I call the operation. In addition, I have extended the procedure to an equivalent of a seven- and eight-rib thoracoplasty. In these cases the operation has been done in one stage, removing the third and fourth ribs and the sixth rib and stripping the periosteum, in a continuous sheet with the intercostal bundles, off the deep surface of the first, second, fifth, and seventh ribs: also the eighth in the eight-rib operation (Plate X).

To date $I$ have done 11 such thoracoplasties. This includes one patient who came to me with a large residual cavity in the costo-vertebral gutter (Plate XIa). He had already had a two-stage eight-rib thoracoplasty with a Semb strip. This had then been followed by an anterior stage and then a redoplasty without obliterating the cavity, nor reducing the four to seven ounces of sputum a day, loaded with tubercle bacilli. In this case (three weeks ago) I stripped the lung out of the gutter and inserted a cylindrical pack (Plate XIb). The sputum is now reduced to one ounce, but is still positive.*

\footnotetext{
*It has since become consistently negative.
} 
Ten cases had positive sputum before operation. Of these, six already show conversion to negative on smear examination and five of these on concentration. Four of the still positive cases have been operated on within the last three weeks.

Various opinions have been expressed on the operation: that of the patient is that there is practically no pain, only a certain amount of discomfort. They feel that they have had an easy time.

The anaesthetist says that even the seven- or eight-rib thoracoplastic is less disturbing to the patient than a four- or five-rib thoracoplasty. The nursing staff say that these patients need amazingly little after-care ; and one, who is Irish, expressed herself that it is possible to nurse twice the number of patients in double the time! The physiotherapist considers. I am doing her out of a job as there is no tendency to stiffness or limitation of arm movements and none to any deformity.

My own view is still one of cautious uncertainty. It would be most unwise of me in this early stage of this endeavour to affirm too emphatically that these packs are producing that collapse of the lung essential for obliterating the cavities and arresting the disease. I can, however, say that I believe this to be the case and that I know that up to date the initial collapse is being maintained. Additional points are that the operation is less severe than the ordinary thoracoplasty; that the equivalent of a seven- or eight-rib thoracoplasty can be done in one stage, and there is no anxiety from paradoxical movement or from deformity, and, further, the postoperative disturbance to the patient is greatly reduced and recovery rapid.

There is one further reason for my caution. The longest case under observation is three months. What will be the state of the lung and the pack in one, two, three, and even five years' time?

On the other hand I think it becomes obvious that if these polythene packs stand up to their trials, the value of them is far-reaching. To mention certain ones only, there is the use of them in dorsal-lobe cavities, in adolescents, and in the reduction of the pleural space after pneumonectomy, by inserting them external to the intercostal muscles.

One patient died. He was a young airman with extensive bilateral disease and cavitation, which was more extensive on the right side. Artificial pneumothorax had been tried without effect; a pneumoperitoneum with a left phrenic crush, resulting in permanent paralysis, had been done eighteen months previously and the pneumoperitoneum was being maintained. He was toxic and in a bad way. After 10 weeks' postural retention the toxaemia had lessened. The pneumoperitoneum was abandoned and I did an anterior costal cartilage resection and inserted a Monaldi tube into the largest cavity, which was posteriorly on the right. From fear of trouble from the Monaldi ceasing to be effective, I started the posterior thoracoplasty, with resection of the fourth to the seventh ribs inclusive. For the next three weeks, until the next stage, I had difficulty with paradoxical breathing, supplemented by a paralysed left dome. For the collapse of the apex I used a pack. This checked all paradoxical movement. A month later I was well satisfied with his convalescence, but then he died suddenly from acute intestinal haemorrhage.

Necropsy absolved the lungs. The right upper lobe was collapsed against the mediastinum and the anterior chest wall. When this was freed the pack was found to be lying in a dry cavity and free from lymph and any adhesions. Dr. Whitwell reports: "The inner wall around the pack is made up of fibrous muscular and adipose tissue, and contains nerve bundles and medium-sized blood vessels, with no sign of foreign-body reaction, spread of tuberculosis, or other inflammatory change. Small foci of calcification are present."

ANAESTHESIA IN ThORACOPLASTY.-The question of anaesthesia in thoracoplasty undoubtedly gives me scope for being provocative-and for your retaliation. For my first cases in 1912-and they were then much more extensive rib resections at one stage than now-I used local anaesthetic only with morphia. Though an adequate analgesia was obtained, I felt the strain was too great and so combined this with just sufficient chloroform vapour to keep the patient unconscious. In 1922-3 I was persuaded to try gas and oxygen, but my anaesthetist, Dr. Halton, and I agreed our previous method was much more satisfactory. I continued happily with the combination of local anaesthetics and chloroform vapour till the barbitones came into use. Since then, and with the increase in specialization of the anaesthetist and the introduction of further poisons, I have become progressively overruled. I agree readily that the modern combinations for operations with an open chest are magnificent, but I unashamedly sigh for my old-fashioned local anaesthetic and chloroform vapour for thoracoplasties. I admit that with this combination there is some postoperative vomiting - but postoperative vomiting is by no means absent with more modern methods. Anyhow, I think this vomiting is a good thing: it gets rid of the sputum, and postoperative collapse is, I believe, 
then less frequent. I remember that Maurer, seeing three of my cases at and after the operation in the chloroform vapour days, was surprised and delighted with the good condition and quick recovery of these cases.

Nowadays if there is no vomiting we sometimes pass a Ryle's tube with suction two to three hours after the operation. The tube may slip through the cords and suck out tenaceous mucus from the trachea. Even if it does not, the stimulation of the cords forces the patient willynilly to cough. A steam tent is also used postoperatively for two or three days.

Surgeons who use some form of general anaesthesia are probably in the minority. The majority use "local" anaesthesia. But the term "local" is a misnomer, because it leaves out of account the heavy doses of hyoscine and morphia or one of the derivatives, which are also used. I dislike this intensive depression of the centres and the abolition of the cough reflex which, I maintain, persists very much longer than with the presentday method of general anaesthesia or my departed chloroform vapour.

\section{Resections for PUlmonary Tuberculosis}

The question of resections for pulmonary tuberculosis was first mooted only a very few years ago. The idea then was formidable. Yet now all thoracic surgeons are convinced that resections have a real value in the treatment of pulmonary tuberculosis. Particularly will this be the case if we can achieve the same reduction in complications by the use of streptomycin as that of Bailey and others in their series of 100 resections so treated. They had 1 per cent only contralateral spread; 1 per cent only bronchopleural fistulae ; 2 per cent empyemas, and a sputum conversion in 94 per cent of living cases.

There are, none the less, many points in dispute, and I believe most surgeons will agree with me when I say we are still feeling our way. My own views are certainly very tentative, and I would suggest broad principles only.

In the first place, I favour pneumonectomy to lobectomy. That does not mean that when you have a tuberculoma of the upper lobe (Plate XII $a$ ), you should do a pneumonectomy: that, par excellence, is a case for upper-lobe lobectomy in preference to every other line of treatment. The reason why in general I do not like a lobectomy is because the disease, apart from tuberculomas, is usually more widely disseminated than can be detected clinically and radiologically, and because nature has been so inconsistent and inconsiderate in not dividing up the lobes of the lungs more completely. Even though resection has been developed to the finer art of segmental resection, I do feel the dangers of exposing infected tissues are great. Added to this is the risk associated with the expansion of the remaining lobe unless steps are taken to prevent this. Secondly, I prefer to do a localized thoracoplasty to an upper-lobe lobectomy in adults, except for a tuberculoma, and except possibly for a case with localized disease and a large retention cyst close to the mediastinum.

Tension cysts of the lower lobe which. have failed to yield to simpler lines of treatment are sometimes an indication for lower-lobe lobectomy, but those in the dorsal division or close to the interlobar fissure may well make the localized resection too dangerous and may necessitate a change of plan to a pneumonectomy, once the chest has been opened. The type of case such as this one (Plate XIIb), with these tension cysts jutting out of a lung well collapsed by an artificial pneumothorax, is unsuited for a thoracoplasty and should be treated by pneumonectomy.

Bronchial stenosis and associated bronchiectasis and cases with caseation rather than cavitation are also indications for resection rather than thoracoplasty.

\section{Medical Aspects of Pulmonary Tuberculosis}

Having talked about the surgical treatment of pulmonary tuberculosis, I turn now to the medical aspect with odd references to pathology and bacteriology. This will doubtless seem the wrong order-like putting the cart before the horse. I entirely agree, but my reason is that, by this order, I may be able better to emphasize the importance of medical treatment. Too often nowadays the patient undergoing unadulterated sanatorium treatment asks: "When am I going to start treatment?" This, of course, is the result of overeducation in the niceties of surgery, and it is much to be deprecated. In the "good old days" before the surgeon started interfering, numbers of patients with tuberculosis were well and truly healed by the physicians: I never use the word " cured" (Plate XIII). Many of these are still amongst the hardest working of our profession. Countless others, with more than a primary infection, have themselves unconsciously effected control of their disease for years and even for life. True, some of these are discovered by the fact that at some later stage they break down again, but would this necessarily have happened if they had known they had had active disease and had 
led the more cautious, meticulous life most of the surgically treated and tuberculosis-conscious cases lead?

There always has been and will be the feeling of necessity to show one's erudition by doing something. In the past it was incantations and the brewing of loathsome concoctions ; then venesection; later the feeding with slugs and snails; then "yadil" by the gallon; tuberculin in all its forms ; then gold. Now almost the first question is: Shall it be an artificial pneumothorax or a pneumoperitoneum or a primary thoracoplasty ?-this latter only, of course, if there is an available surgeon ; otherwise it is not considered. Soon it will be streptomycin-till the tubercle bacillus adopts an additional covering to its (I am told) hypothetical fatty or lipoid envelope to protect itself against the new menace to its existence.

There is much to be said for the sanatorium physician who, while wise in his knowledge of surgery, puts his patient to bed, studies his case from all angles, watches his response to sanatorium regime, and balances the pros and cons before putting the case up for ancillary treatment: who, further, when and as long as this patient is responding favourably and progressively to this sanatorium regime, continues it. There are many patients, admittedly, for whom it is obvious from the moment they are diagnosed that surgical treatment is essential. For some this needs to be with the least possible delay: for others only after a period of medical treatment to stabilize the disease and to localize it as much as possible. Who is the better judge of the psychological moment for more intense measures than the physician in constant charge of the case, yet who also works in close co-operation with a surgeon ? But this physician is also the clearer-sighted person who knows when not to invite surgical intervention. Certainly my most pleasing successes are those I can send out healed by sanatorium treatment alone.

I would emphasize that every patient is a separate individual, mentaliy and physically, in his resistance to the disease and in his response to treatment. There can be no such thing as successful mass treatment. Each individual must be individually assessed; not alone on his $x$-ray pictures, not alone on the clinical findings, but on these, on his past history, and on the study of the patient himself. Radiographs are as essential as the clinical findings, but equally the clinical examination is as essential as are the radiographs.

The resistance to the disease varies in each individual, but alters throughout the years of his life. In some the resistance can never be bene- ficially improved. Fortunately in many this can be done: in some quickly; but for others it takes months before a response can be obtained.

In discussing sanatorium treatment $I$ am discounting here the present-day difficulties of shortage of beds, of staff, and of food. When circumstances permit treatment as one would wish, I deplore the rush to ancillary treatment: but when conservative treatment is indicated, I deplore equally the profitless haste to get patients up for two, four, or six hours a day, while they still have perhaps some pyrexia, active disease, and a positive sputum. That is not sanatorium treatment as it was originally meant and still should be.

One of my mottoes is " fitness rather than fatness," but that does not mean that the patient who needs rest to control the active disease is to be put on exercise. Exercise should start only when the condition is stabilized, when the pyrexia is controlled, and when the active exudative lesions are fibrosing.

I fear that the tendency to let the patient up to loaf and roam through the day is sometimes an unconscious escape on the part of the physician from his obligations of the more time-consuming measures to alleviate the patient's boredom. This boredom is a serious menace to contentment and therefore to recovery. But should it not be a part of the understanding of the physician and of his job to counteract this boredom while still maintaining the rest in bed which is essential ?

Sedimentation Rate.-One word as a footnote to my remarks on assessing the patient: and the blood sedimentation rate is not worth more than a footnote. If the patient is obviously going downhill and the sedimentation rate is low (after all compensations have been made), how much wiser are you ? If you think the patient is healed and the blood sedimentation rate is high, then you do need the sedimentation rate in your repertory.

Postural Retention.-This discourse on rest treatment leads me to the consideration of the principle of postural retention with which DillwynThomas and others have been experimenting. It is a treatment that undoubtedly demands a high degree of concentration and fortitude from all concerned. It is too early to appreciate yet the extent of the merits of this line of treatment, as Dillwyn-Thomas has been the first to acknowledge, but some of the results can be justly referred to as startling. Unquestionably the method is worth further study. Two changes can be seen in the radiographs: the one a reduction in the size of the cavity, the other is that there is now secretion 
part filling the cavity and showing a horizontal fluid level. Whatever was the case before inversion, the cavity is no longer a tension one.

It would seem probable that the removal of secretions from the mouth of the bronchus reduces the inflammatory changes and allows of freer air entry and egress, and that the sagging of the mediastinum and rise of the dome together with better ventilation of the lung, and possibly associated improved circulation, are all contributory factors.

One point is clear, the reduction in size of the cavity is temporary only, but the changes may so improve the general condition of the patient as to allow more extensive remedial measures of a more permanent nature to be undertaken.

SPUTUM Conversion.--Is it not time we became more precise as to when a patient is a tuberculinpositive or negative case? I admit that when a sputum-positive case has had an operation and three successive smears are negative, it is very comforting to one's self-respect. How disturbing, then, to one's attempts at self-deception when some enquiring busybody produces a positive result from a laryngeal swab or a gastric lavage or, later, reports that the culture was positive. I am glad to note that we are recently becoming more conscious of the need for distrusting, except as a general indication, the findings from direct smears. Yet, in the journals, there is frequent omission, when reporting sputum conversions, of the methods used.

Now I want to ask the bacteriologists and pathologists some questions. Why is it that in certain cases with a purulent sputum no tubercle bacilli can be found on repeated examinations, yet the bacilli can be demonstrated in a smear from a laryngeal or bronchial swab or by gastric lavage?

Again, why in some cases of undoubted tuberculosis is it impossible to find tubercle bacilli by any means, yet in others, seemingly less active and less extensive, are the tubercle bacilli in such abundance? No one as yet has given me a satisfactory answer.

Is there any correlation between such findings and the resistance of the patient to the disease ? I am told that experimentally in animals, lesion for lesion, the guinea-pig-least resistant to the disease-produces far fewer tubercle bacilli than the rat-which is far more resistant; and that the rabbit, intermediate in its resistance, produces more tubercle bacilli than the guinea-pig, but fewer than the rat. Can we apply this to the human, and conclude that the more tubercle bacilli the better the resistance? If not, why not ? I feel we need more help than we have had hitherto in the living pathology.

\section{Milestones in Treatment}

Finally, I am tempted to glance over the years of progress and to try to pick out the essential advances - the milestones in the development of the treatment of pulmonary tuberculosis. I suppose the first must be the recognition of the prime essentials, of rest, of fresh air, and of proper feeding. Hence the development of the sanatorium. The next milestone would be the practical application of artificial pneumothorax treatment by Forlanini in 1888: though this was first suggested in 1822 by Carson.

The next milestone was the principles of thoracoplasty as planned by Friedrich, Sauerbruch, and Wilms. The most recent milestone has been the application of resections and, we will hope, chemotherapy by streptomycin.

Yet there is one other milestone which seems to me as important and of almost greater portent for the future. I refer to the spirit of harmony and co-operation between the members of the diverse branches of the medical profession.

In the fifteenth century some faculties were induced to grant licences to practise surgery to the less clever pupils " so long as he does not exercise the art of medicine and does not call himself a physician." In the twentieth century, in 1915 to be precise, at a meeting of the Medical Society in London to discuss the treatment of pulmonary tuberculosis, I attempted to talk on the surgical treatment, but was ordered by the President to stand down on the grounds that my remarks had nothing to do with the subject under discussion. Yet to-day the very existence of this Thoracic. Society emphasizes the tremendousness of the change of heart and the team spirit which has arisen. Physicians and surgeons now work in close collaboration, and with these the radiologists, the pathologists, the physiologists, and anatomists: none jealous of the other, but all striving with one object: the means of treating and of healing the tuberculous patient.

But, in the treatment of the patient, with all this pooling of scientific knowledge and research for newer and better methods towards success, there is one factor that must be common to all, and that is understanding. 